Document downloaded from:

http://hdl.handle.net/10251/160319

This paper must be cited as:

Guardiola, C.; Climent, H.; Pla Moreno, B.; Real, M. (2019). Control-oriented modelling of three-way catalytic converter for fuel-to-air ratio regulation in spark ignited engines.

Proceedings of the Institution of Mechanical Engineers Part D Journal of Automobile Engineering. 233(14):3758-3774. https://doi.org/10.1177/0954407019833822

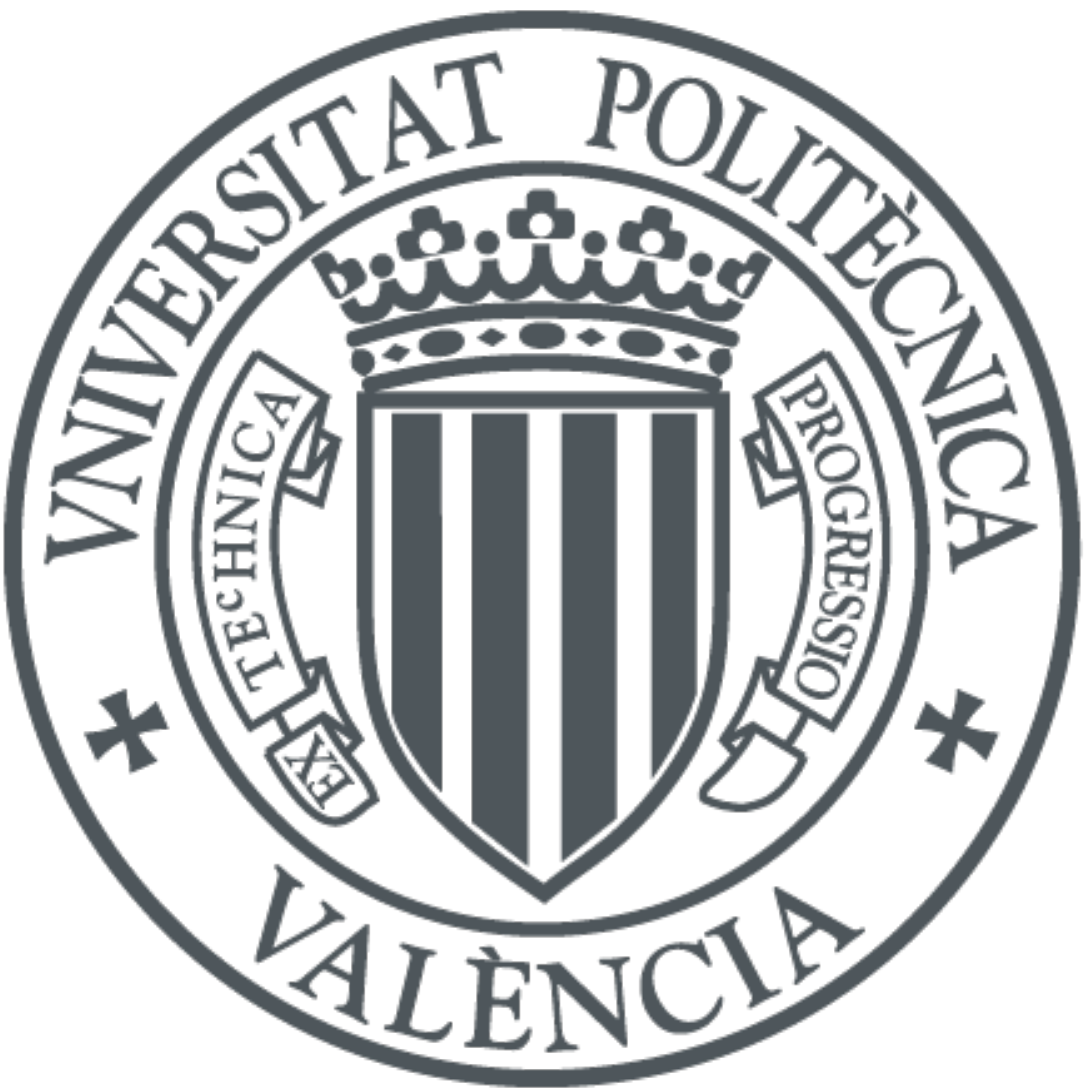

The final publication is available at

https://doi.org/10.1177/0954407019833822

Copyright SAGE Publications

Additional Information 


\title{
Control-oriented modelling of three-way catalyst for fuel-to-air ratio regulation in spark ignited engines
}

\author{
Carlos GUARDIOLA ${ }^{1}$, Héctor CLIMENT ${ }^{1}$, Benjamín PLA ${ }^{1}$, Marcelo REAL ${ }^{1}$
}

\begin{abstract}
The purpose of this paper is to introduce a grey-box model of three-way catalyst (TWC), which is capable of estimating the oxygen storage level (OSL) to aid the fuel-to-air ratio control in spark ignited (SI) engines. As it is well-known, the prime parameter that drives the transient dynamics in current TWCs is their capability to store a certain amount of oxygen, then allowing to oxidise some pollutant species such as carbon monoxide (CO) or hydrocarbons (HC) even at rich conditions during short periods of time. Since OSL is considered a good indicator of the catalyst state but it cannot be directly measured, a model based real-time capable estimation like the one proposed in this paper could be valuable. The model accounts for oxygen storing as well as oxidation and reduction of the main species involved, taking as inputs fuel-to-air equivalence ratio, air mass flow, temperature and gas composition at TWC inlet. From these inputs OSL and brick temperature are calculated as model states, which finally provide the gas composition downstream of the catalyst as output. Additionally, a simplified model of narrowband $\lambda$ sensor is included, it provides a voltage from gas composition at the outlet of the catalyst and allows to assess the model behaviour by comparison with the on-board $\lambda$ sensor measurements. Finally, the validation of the model performance by means of experimental test as well as different practical cases, where the benefits of OSL estimation plays a key role, are introduced.
\end{abstract}

\section{Keywords}

Spark ignited engine, Control-oriented modelling, Fuel-to-air ratio control, Three-way catalyst

\section{Introduction}

Nowadays pollutant emissions are an important issue, in fact, some European cities have begun to implement traffic restrictions in an attempt to improve air quality, therefore, the improvement and adaptation of exhaust gas aftertreatment systems in spark ignited engines (SIE) takes special relevance. In this sense, the best trade-off between compactness and cost-performance is provided by three-way catalytic converter (TWC) based systems. This converter allows to oxidise hydrocarbons (HC) and carbon monoxide (CO) while simultaneously reducing nitrogen oxides $\left(\mathrm{NO}_{\mathrm{x}}\right)$. However, to achieve a high conversion efficiency for all the species involved, the fuel-to-air equivalence ratio (hereinafter FAR) should be accurately controlled close to stoichiometric. Taking into account the low emission levels allowed by the current legislation and the future zero emissions trend, the strategies based on TWC control oriented modelling are indispensable.

The key of this approach is supported by its capability to provide insights about the instantaneous state of the converter, especially in terms of oxygen storing level (OSL), which is a parameter tightly related with the conversion efficiency during FAR transients. As it usually happens, the restriction in the operating conditions of a system force other coupled subsystems to work out of its operating range. In this regard, some typical driving conditions such as transient phases, injection cut-off or start-stop systems among others, lead to impose FAR different from stoichiometric and thus making the TWC to work outside of design conditions and preventing it from getting proper conversion efficiency ${ }^{1}$. All of them are typical situations in which knowing the TWC state could be really useful to control properly the converter dynamics. Moreover, TWC control oriented modelling is also a key concept from the point of view of the engine aftertreatment diagnosis. For example, to estimate the TWC ageing level, the nominal oxygen storing capabilities (OSC) can be compared with the corresponding model estimation after some period of time.

A lot have been written regarding TWC and $\lambda$ sensors modelling in last years, nevertheless, according to the authors' point of view there is still a not fully covered requirement in this field, that is, control oriented models able to provide not only OSL estimations, but also information about the concentration of the main pollutant species downstream of the TWC with real-time capabilities. Detailed chemical first-principle models of both, $\lambda$ sensor $^{2}$ and TWC has been developed over the past three decades. These models allow a deeper understanding of the phenomena related to the dynamic behaviour of the system, dealing with different complexity levels, from multi-dimensional models ${ }^{3-10}$ to more common one-dimensional approaches as ${ }^{11-21}$. Of course, all of them provide wide and accurate

${ }^{1}$ CMT-Motores Térmicos, Universitat Politècnica de València, Valencia, Spain

Corresponding author:

Marcelo REAL, Camino de Vera, s/n 46022 Valencia, Spain

Email: marreami@mot.upv.es 
information regarding the converter state, but they cannot be used for real-time applications (RTA), which rule them out for control purposes. On the other hand, the integratortype or black-box models ${ }^{22-28}$ were the only feasible option for OSL estimation in RTA some years ago, when the computational capabilities of the common ECUs were rather limited, but they are not accurate enough for today's requirements. For example, with an integrator-type storing model based on the inlet FAR, independently of the previous evolutions, a FAR equal to stoichiometric leads the OSL to reach immediately steady state conditions, since it does not account for the exhaust gas composition at catalyst inlet.

An intermediate approach is followed in other publications ${ }^{29-34}$, which takes into account a few chemical reactions but keeping the real-time capabilities by means of lumped-parameter models, usually zero-dimensional or quasi-dimensional with one or several nodes axially distributed along the TWC length. They often supply OSL estimations and FAR in the tail pipe with a proper costperformance trade-off, but not all of them provide information about the concentration of the main pollutant species involved downstream of the TWC. It could be useful in order to implement a control strategy based on emissions, thus controlling FAR to keep the main pollutant species below a threshold depending on different criteria. The present paper proposes a zero-dimensional control-oriented and real-time capable model with lumped-parameter kinetics, which is able to provide reasonable estimations of OSL, brick temperature as well as the main chemical species involved at TWC outlet. In the current approach, only one node is considered, but the model can be extended to deal with several nodes if an axial distribution is needed.

\section{Tools}

All data collected for model fitting and validation is obtained by means of experimental test in the facilities of CMT-Motores Térmicos, at the Universitat Politècnica de València. The engine test bench is especially equipped for exhaust gas measurements, with Horiba MEXA-ONE analyser to measure $\mathrm{CO}, \mathrm{CO}_{2}, \mathrm{HC}, \mathrm{CH}_{4}, \mathrm{O}_{2}, \mathrm{NO}, \mathrm{NO}_{2}, \mathrm{NO}_{\mathrm{x}}$ and FAR. Two faster Cambustion analysers, in particular models NDIR500 and CLD500, have been used for CO and $\mathrm{NO}_{\mathrm{x}}$ respectively, at the inlet and outlet of the TWC. $\mathrm{H}_{2}$ measurement, however, is not available. Regarding the internal combustion engine, one representative of the current state of the art, turbocharged gasoline direct injection (GDI) engine has been used, it has 3 cylinders and a total displacement of 1.2 litres. The intake and exhaust lines are instrumented with average pressure and temperature sensors at the inlet and outlet of each element. The advantage of using a real engine to collect the required data lies in the fact that the TWC is exposed to a gas flow totally equivalent to the one expected in real driving conditions, i.e., with similar temperatures, mass flows, pulsed air flow and same exhaust gas composition, which is particularly relevant.

Regarding the catalytic converter used, it is a full volume TWC, so $\lambda$ sensors are placed at the inlet and outlet, that is, there is not an intermediate FAR measurement as occurs with partial volume catalysts. It is fully instrumented to measure temperature at several points longitudinally distributed and at different depths inside the brick. Pressure sensors and $\lambda$ sensors are also placed at the inlet and outlet. Particularly, two switch-type and two wideband $\lambda$ sensors (also called binary and linear sensors respectively) measure FAR upstream and downstream of the TWC. Finally, two converters with different ageing levels complete the equipment available, one totally new and one aged TWC.

\section{TWC model description}

\subsection{Requirements}

The main parameter that drives the transient dynamics in current catalysts, is their capability to store and release a certain amount of reducing and oxidizing species with the aid of noble metals and ceria, then allowing to oxidise some pollutant species such as $\mathrm{CO}$ or $\mathrm{HC}$ even at rich conditions during short periods of time. The relative oxygen level stored in ceria (OSL) with respect to the total TWC oxygen storing capabilities (OSC), is considered a good indicator of the catalyst state ${ }^{1,35}$, but it cannot be directly measured by means of onboard sensors. Thus, a model based and real-time capable estimation is needed to control the FAR in a further accurate way than currently, thereby reducing pollutant emissions even more. In this sense, the target of the model presented in this paper is to supply information about OSL and tail pipe emissions. The first one allows to implement a FAR control strategy based not only on FAR as usual, but also on the amount of oxygen stored. Regarding tail pipe emissions, they represent the input signal for the downstream $\lambda$ sensor sub-model, which could be used in future works to implement an on-line observer, by comparing the sensor model output with the on-board sensor measurement. Of course, in order to fulfil these objectives the model must offer low computational requirements as to be implemented in a rapid prototyping system and also being accurate enough for the present purposes.

\subsection{Model structure}

The model introduced in this paper intends to be as simple as possible in order to fulfil the FAR control requirements with the minimum computational cost, thus detailed physical approaches have been dismissed. Those models that are not able to provide information regarding the main species involved at the catalyst outlet have also been rejected for the present work. An intermediate approach has been followed instead, a zero-dimensional lumped-parameter model with a single node is considered for simplicity, although the model is ready to deal with a quasi-dimensional extension based on axial discretization of the TWC with the aid of additional nodes.

The model inputs are engine speed, throttle and FAR upstream of the TWC, which are all available in current ECUs, either by direct measurement or indirect calculation. From previous signals, a static feed gas sub-model supplies the inputs for the oxygen storing and thermal submodels. These ones provide the two states of the TWC considered, OSL and brick temperature respectively. Tail pipe temperature and emissions such as $\mathrm{NO}_{\mathrm{x}}, \mathrm{CO}, \mathrm{CO}_{2}$, $\mathrm{HC}$ and $\mathrm{O}_{2}$ represent the model outputs. Finally, since $\lambda$ sensors response time is faster than TWC dynamics, a static 


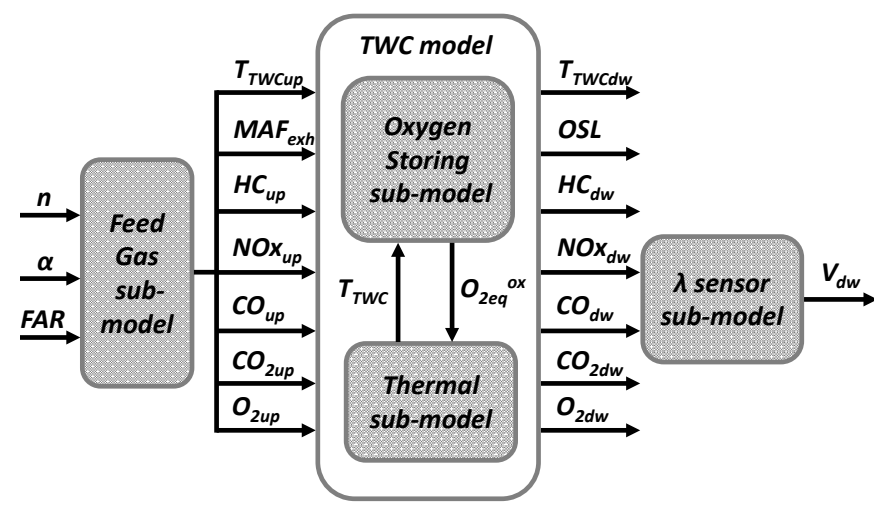

Figure 1. Model structure.

$\lambda$ sensor sub-model estimates the voltage of the narrowband $\lambda$ sensor downstream of the TWC taking as inputs $\mathrm{NO}_{\mathrm{x}}$ and $\mathrm{CO}$ concentrations at catalyst outlet. Therefore, four different sub-models makes up the complete structure as it is shown in figure 1 .

3.2.1 Feed gas sub-model This sub-model provides the inputs for the TWC model as function of the operating conditions. Steady state values of temperature and gas composition previously measured at catalyst inlet are implemented in lookup tables as function of engine speed and load as well as fuel-to-air equivalence ratio. Exhaust gas composition depends on combustion chamber conditions, whose dynamics are much faster than TWC ones, thus neglecting exhaust gas dynamics to estimate emissions upstream of the TWC is a reasonable approach. In spite of that, a first order filter has been fitted to experimental data and added to the outputs of the steady-state model in order to improve the model performance in transient conditions. The sub-model outputs are TWC inlet temperature, exhaust mass flow and the concentration of the main exhaust species: $\mathrm{NO}_{\text {xup }}, \mathrm{CO}_{u p}, \mathrm{CO}_{2 u p}, \mathrm{HC}_{u p}$ and $\mathrm{O}_{2 u p}$. In figure 2, several FAR steps have been performed with the engine running at $1250 \mathrm{rpm}$ and $25 \mathrm{Nm}$. The values provided by this submodel are accurate enough for the sub-model purposes at steady state, although in case of bias error, of course this error would be transmitted to the TWC model disturbing the outlet predictions. During transient phases, the outputs of the lookup tables follow directly the dynamics imposed by their inputs, in particular the dynamic of the FAR in figure 2. This is a sensible approach for gas composition since, in fact, it drives the sensors response. But even in that case some discrepancies can appear due to the nonlinearity as well as to the different weight of each species on FAR. As shown in this figure, the values provided by lookup tables show a slightly faster response than the measurements, that is why a first order filter is applied to the steady-state model outputs. Regarding inlet temperature, the evolution in figure 2 shows a low sensitivity of temperature to FAR variations, but that is not the case for engine speed and load. The dynamic behaviour of exhaust temperature is driven by transport and heat transfer phenomena from exhaust pipes to TWC inlet. A detailed modelling of the exhaust line is out of the scope of the present approach, since the current TWC model is oriented to control purposes. Moreover, whatever the complexity of the approach used, an estimation of the
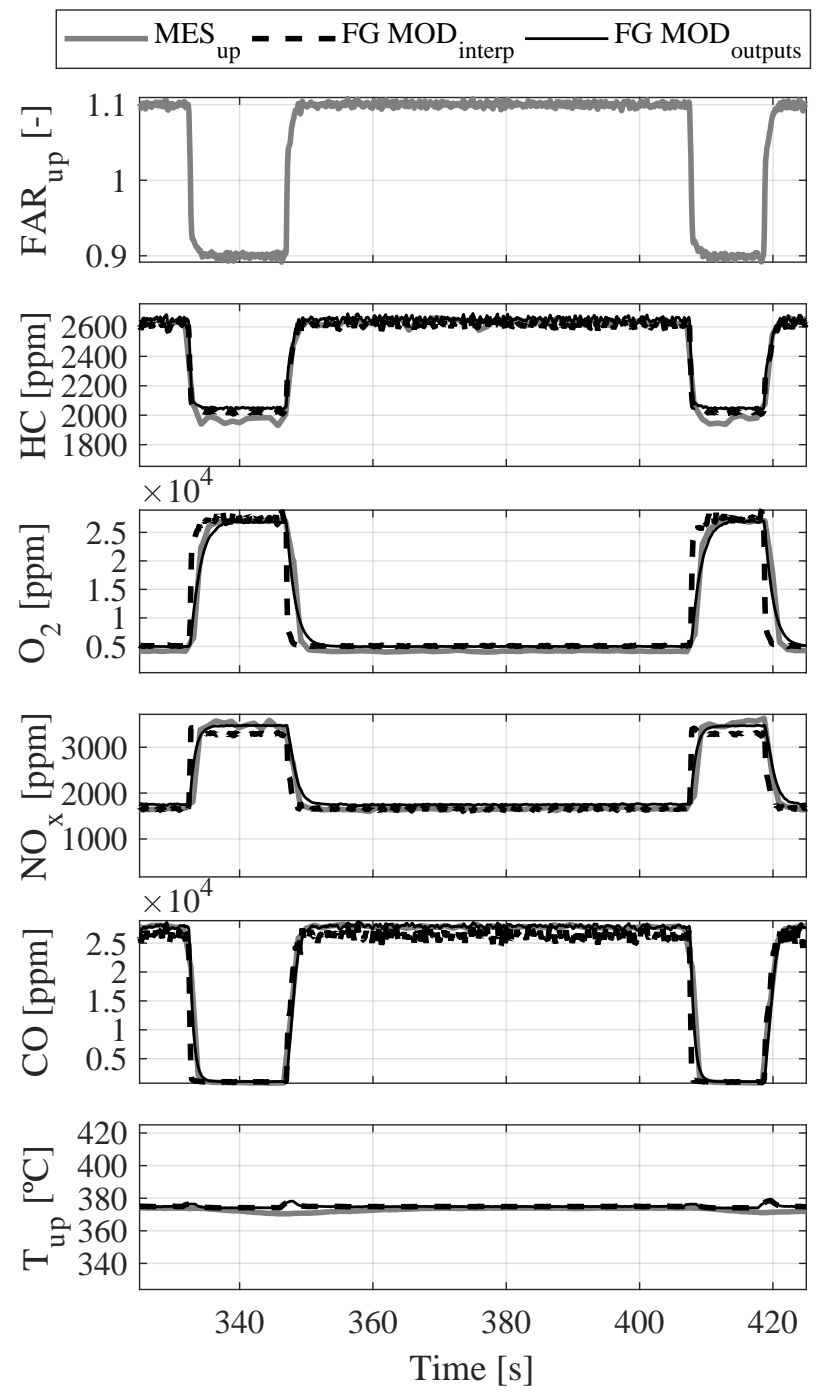

Figure 2. Comparison between feed gas sub-model outputs and measurements for FAR steps at $1250 \mathrm{rpm}$ and $25 \mathrm{Nm}$.

$M_{\text {ES }}, F G M O D_{\text {interp }}$ and FG MOD outputs $_{\text {represent }}$

measurements, direct interpolation in lookup tables and outputs of the feed gas sub-model respectively.

temperature entering the system is needed because there are not temperature sensors available on-board along the exhaust. Therefore, in order to estimate the catalyst inlet temperature, the same approach applied for gas composition is chosen. In this case the use of a first order filter is strongly required because the transient response provided by the steady model is faster than real, due to the thermal inertia of the exhaust components.

3.2.2 TWC reactions considered The model accounts for three reactions in noble metal, namely $\mathrm{HC}$ and $\mathrm{CO}$ oxidation as well as $\mathrm{NO}_{\mathrm{x}}$ reduction:

$$
\begin{aligned}
\mathrm{C}_{x} \mathrm{H}_{y}+\left(x+\frac{y}{4}\right) \mathrm{O}_{2} & \rightarrow \mathrm{CO}_{2}+\frac{y}{2} \mathrm{H}_{2} \mathrm{O} \\
\mathrm{CO}+\frac{1}{2} \mathrm{O}_{2} & \rightarrow \mathrm{CO}_{2} \\
\mathrm{NO}+\mathrm{CO} & \rightarrow \mathrm{CO}_{2}+\frac{1}{2} \mathrm{~N}_{2}
\end{aligned}
$$


Regarding the storing reactions, only oxygen is considered to be able to oxidise ceria, thus ceria oxidation by means of $\mathrm{NO}_{\mathrm{x}}$ is neglected. Nevertheless, for ceria reduction both $\mathrm{HC}$ and $\mathrm{CO}$ are taken into account, while $\mathrm{H}_{2}$ is not considered. This set of reactions is widespread used in the literature ${ }^{12,36,37}$.

$$
\begin{aligned}
\mathrm{Ce}_{2} \mathrm{O}_{3}+\frac{1}{2} \mathrm{O}_{2} & \rightarrow \mathrm{CeO}_{2} \\
\mathrm{CO}+2 \mathrm{CeO}_{2} & \rightarrow \mathrm{Ce}_{2} \mathrm{O}_{3}+\mathrm{CO}_{2} \\
\mathrm{C}_{x} \mathrm{H}_{y}+(2 x+y) \mathrm{CeO}_{2} & \rightarrow \\
\rightarrow\left(x+\frac{1}{2} y\right) \mathrm{Ce}_{2} \mathrm{O}_{3} & +\quad x \mathrm{CO}+\frac{1}{2} y \mathrm{H}_{2} \mathrm{O}
\end{aligned}
$$

In the present approach $\mathrm{O}_{2}, \mathrm{CO}$ and $\mathrm{HC}$ reactions (eqs. 1 and 2) follow the Langmuir-Hinshelwood mechanism, that is, their adsorption in the noble metal is needed prior to react. $\mathrm{NO}_{\mathrm{x}}$ reduction (ec. 3), in turn, is considered as Eley-Riddeal mechanism, thereby it is adsorbed in noble metal and reacts with $\mathrm{CO}$ in gas phase. Whether there is still oxygen excess after reacting over noble metal surface (eqs. 1 and 2), then oxygen is stored by means of ceria oxidation (eq. 4). In the same way, when there is a lack of oxygen at catalyst inlet, $\mathrm{CO}$ and $\mathrm{HC}$ are desorbed and the oxygen previously stored is used to oxidise $\mathrm{CO}$ and $\mathrm{HC}$ in gas phase (ecs. 5 and 6). Thus, the oxidation of reducing species with ceria is also considered that follows the Eley-Riddeal mechanism as in the case of $\mathrm{NO}_{\mathrm{x}}$ reduction. This is conceptually the followed approach, but chemical reaction rates are not really implemented as such. To simplify, an algebraic mass balance is considered for each species instead, thereby the reactions progress depending on the availability of its respective reactants. In this sense $\mathrm{HC}, \mathrm{NO}_{\mathrm{x}}$ and $\mathrm{CO}$ are adsorbed and desorbed in the same time step when they cannot react because of the lack of one of the needed reactants, hence $\mathrm{O}_{2}$ is the only species that can be stored (with ceria) during several time steps. Additional reactions as water-gas shift and steam-reforming reactions have been neglected in order to simplify the model complexity, in any case, their practical effects concerning $\mathrm{HC}$ and $\mathrm{CO}$ oxidation after a lean to rich step can be partially replaced by oxygen stored in ceria. In the same way, the effect of $\mathrm{H}_{2}$ on the downstream narrowband $\lambda$ sensor cannot be taken into account. These assumptions as well as its practical consequences will be discussed in next sections.

3.2.3 Oxygen storing sub-model The adsorbed mass of each species is calculated by means of their respective adsorption rates $\left(\mu_{x}\right)$, which depend on OSL:

$$
\begin{aligned}
m_{O_{2}} a d s & =\mu_{O_{2}}(O S L) * m_{O_{2} u p} \\
m_{N O_{x} a d s} & =\mu_{N O_{x}}(O S L) * m_{N O_{x} u p} \\
m_{C O a d s} & =\mu_{C O}(O S L) * m_{C O u p} \\
m_{H C a d s} & =\mu_{H C}(O S L) * m_{H C u p}
\end{aligned}
$$

All the adsorbed mass of each chemical species does not necessarily reacts as it happens when an efficiency rate is imposed. Instead, the portion of the adsorbed mass that finally reacts depends on the availability of other reactants, thereby the adsorbed mass can be desorbed in the same time step when it does not react with other species. The only exception is $\mathrm{O}_{2}$, that can be stored in ceria during several time steps until being oxidized by $\mathrm{HC}$ or $\mathrm{CO}$, if there is lack of oxygen at catalyst inlet.

The mass balances are based on equivalent species. Since the model only accounts for few reactions while the actual chemistry inside a TWC is quite more complex, the use of stoichiometric rates does not provide good results as expected. That is why equivalence parameters $\left(k_{x}\right)$ have been used to convert each species into its corresponding equivalent:

$$
\begin{aligned}
m_{\mathrm{HC} q} & =k_{(\mathrm{CO} \rightarrow \mathrm{HC})} * m_{\mathrm{CO}} \\
m_{\mathrm{O}_{2} e q} & =k_{\left(\mathrm{HC} \rightarrow \mathrm{O}_{2}\right)} *\left(m_{\mathrm{HC}}+m_{\mathrm{HC} q}\right) \\
m_{\mathrm{CO} \mathrm{eq}} & =k_{\left(\mathrm{NO}_{x} \rightarrow \mathrm{CO}\right)} * m_{\mathrm{NO}_{x}}
\end{aligned}
$$

Thus, reactions 1-6 can be outlined as:

$$
\begin{aligned}
O_{2(S P-N M)}+O_{2 e q(S P)} & \rightarrow C O_{2 e q(G P)} \\
C O_{(G P)}+C O_{e q(S P)} & \rightarrow C O_{2 e q(G P)} \\
O_{2(S P-N M)} & \rightarrow O_{2(S P-C E R I A)}(16) \\
O_{2(S P-C E R I A)}+O_{2 e q(G P)} & \rightarrow C O_{2 e q(G P)}
\end{aligned}
$$

Subscripts 'SP' and 'GP' indicate solid and gas phase respectively, while subscripts 'SP-NM' and 'SP-CERIA' distinguish between oxygen adsorbed in noble metal and oxygen stored in ceria.

An additional parameter called $\mathrm{OSL}_{r e f}$ has been introduced in order to deal with the fact that oxygen storage is an equilibrium controlled process ${ }^{38,39}$. That is, the OSL cannot reach a value equal to 1 or 0 just when there is an oxygen excess or lack respectively but when the chemical equilibrium between solid and gas phases is fulfilled. This parameter symbolizes the OSL value for which the oxygen storing process reaches the chemical equilibrium given a certain exhaust gas composition at steady state. For each operating point in terms of engine speed $(n)$ and load $(\alpha)$, the best parameter to quantify the mentioned exhaust gas composition is FAR upstream of the TWC, therefore the reference OSL value depends on the operating point and FAR at catalyst inlet:

$$
O S L_{r e f}=f(F A R, \alpha, n)
$$

First, the available $\mathrm{O}_{2}$ is compared with the equivalent $\mathrm{HC}$ and $\mathrm{CO}$ to check whether all the reducing species adsorbed can be oxidized or not. When there is enough $\mathrm{O}_{2}$ availability, the mass of HC and CO downstream of the TWC is exactly the amount of each one that has not been adsorbed (figure 3 ), thereby in this case the adsorption coefficient is behaving as a conversion efficiency. Next, the adsorbed $\mathrm{NO}_{\mathrm{x}}$ can react with $\mathrm{CO}$ in gas phase (figure 4), that is, with the proportion of $\mathrm{CO}$ which has not been previously adsorbed and oxidized with $\mathrm{O}_{2}$.

The excess of $\mathrm{O}_{2}$ can be stored in ceria (figure 3) as long as the current OSL is lower than the reference OSL $\left(\mathrm{OSL}_{r e f}\right)$ for the corresponding operating conditions.

If that is not the case, then the surplus $\mathrm{O}_{2}$ is desorbed. On the contrary, when there is not enough $\mathrm{O}_{2}$ availability 


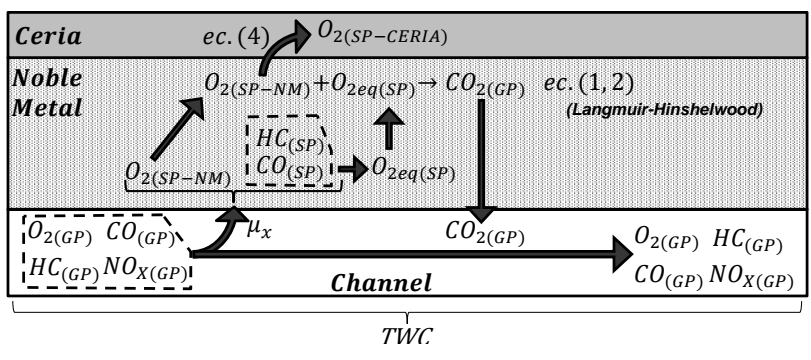

Figure 3. Oxidation reactions when there is excess oxygen.

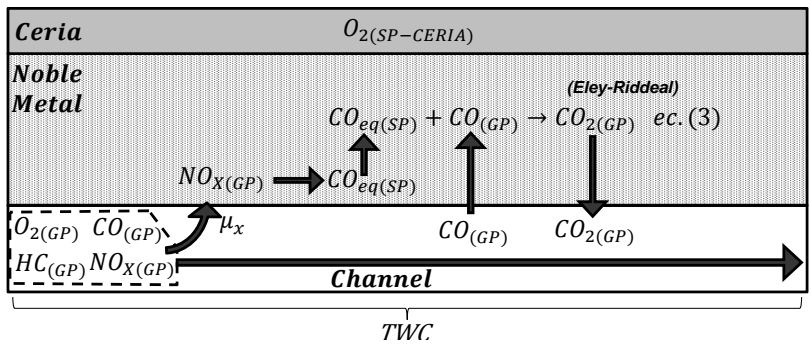

Figure 4. Reduction reaction.

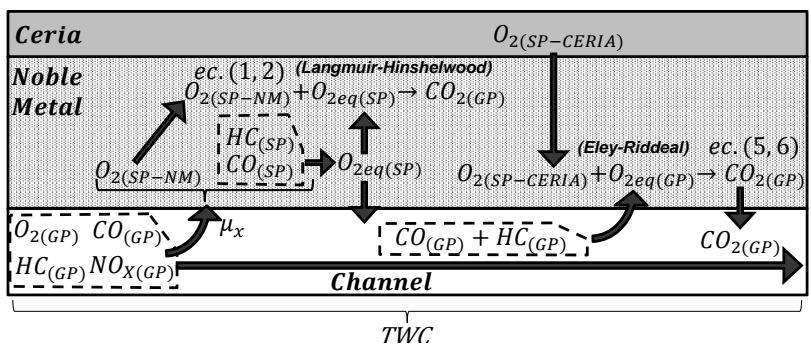

Figure 5. Oxidation reactions when there is lack of oxygen.

only the proportional amount of equivalent $\mathrm{HC}$ and $\mathrm{CO}$ is oxidized and the rest is desorbed (figure 5). Again, the adsorbed $\mathrm{NO}_{\mathrm{x}}$ can react with the $\mathrm{CO}$ in gas phase, that is, the proportion of $\mathrm{CO}$ which has been previously desorbed together with the incoming $\mathrm{CO}$ gas. Under these conditions, the lack of $\mathrm{O}_{2}$ can be compensated by using the previously stored $\mathrm{O}_{2}$ in ceria whether current OSL is higher than $\mathrm{OSL}_{r e f}$, thus oxidizing $\mathrm{HC}$ and $\mathrm{CO}$ in gas phase, either they have not been adsorbed or they have been desorbed due to the lack of $\mathrm{O}_{2}$ in noble metal (figure 5).

Finally, $\mathrm{CO}_{2}$ at the outlet is calculated as the addition of two terms, $\mathrm{CO}_{2}$ at the inlet and $\mathrm{CO}_{2}$ generated with the oxidation of $\mathrm{HC}, \mathrm{CO}$ and $\mathrm{NOx}$. In the same way, $\mathrm{O}_{2}, \mathrm{HC}, \mathrm{CO}$ and NOx at catalyst outlet are calculated as the difference of two terms, one of them accounts for the amount of each one upstream the TWC and the other one accounts for the amount of each one which have reacted with other reactants.

3.2.4 Thermal sub-model An accurate prediction of the TWC temperature requires a detailed model based on first principles, since thermal dynamics are strongly dependent on axial distribution, especially during the heating-up process. Therefore a lumped-parameter model as the one presented will not be able to fulfil the requirements if an accurate temperature prediction is needed. The controloriented model proposed is essentially focused on after heating-up operating conditions, when the requirements in terms of temperature prediction are not so demanding. That is, once the temperature is such that the activation energy of all reactions involved is exceeded, conversion efficiency is mainly dependent on both fuel-to-air ratio at catalyst inlet and oxygen stored in ceria. Consequently for the current approach temperature does not play a key role on its capability to predict tailpipe emissions and outlet FAR. Particularly, in the present model the temperature prediction is used for two purposes: in order to slightly adjust the conversion efficiency above light-off; as well as to take into account the conversion efficiency drop in case of reaching temperatures below light-off, for example, as a consequence of a long enough period under fuel injection cut-off.

TWC temperature is calculated through an energy balance that accounts for three terms: the energy exchange due to the thermal state of the inlet flow $\left(\mathrm{Q}_{\mathrm{IF}}\right)$, the energy generated inside the TWC due to the oxidation processes ( $\mathrm{Q}_{\mathrm{OX}}$ ) and the energy exchange with the environment by convection (QENV).

$$
\frac{\mathrm{d} Q_{T W C}}{\mathrm{~d} t}=Q_{I F}+Q_{O X}+Q_{E N V}
$$

While tailpipe temperature is calculated analogously but just considering the TWC energy and heat loses to the environment.

$$
\frac{\mathrm{d} Q_{T P}}{\mathrm{~d} t}=Q_{T W C}+Q_{E N V}
$$

3.2.5 $\lambda$ sensor sub-model Considering the fact that $\lambda$ sensors response time is faster than TWC dynamics, a static narrowband $\lambda$ sensor model has been implemented. The voltage provided by the sensor model downstream of the TWC is obtained as the addition of three terms: the first term takes into account the reference voltage, i.e., the one that provides the sensor when it is exposed to a neutral gas. The second and third terms are non-linear functions $\left(\Psi_{L E A N}\right.$ and $\Psi_{R I C H}$ ) that allow to pull up or down the reference voltage due to the presence of reducing or oxidizing species respectively. In particular, $\mathrm{NO}_{\mathrm{x}}$ concentration at catalyst outlet is used to reduce the reference sensor voltage, since $\mathrm{NO}_{\mathrm{x}}$ emissions are the final consequence of an $\mathrm{O}_{2}$ excess. Even at slightly rich conditions could be a non-negligible amount of oxygen downstream of the TWC (non-ideal combustion process), but only when there is a certain amount of $\mathrm{NO}_{\mathrm{x}}$ the TWC is really working at lean conditions. On the other hand, $\mathrm{CO}$ is the reducing species used to pull up the reference voltage due to their good correlation as it is wellknown $2,40,41$.

$$
V d w=V_{\text {ref }}+\Psi_{L E A N}\left(N O_{x}\right)+\Psi_{R I C H}(C O)
$$

\section{TWC model fitting \& validation}

For easier understanding of the fitting process, it will be divided into different steps as it is shown in figure 6 . First, the setting of the equivalence parameter for each chemical reaction $\left(k_{x}\right)$ is carried out in Step 1 . Next, in Step 2, the narrowband $\lambda$ sensor parameters are also fitted. Once finished these two steps for any operating point, 


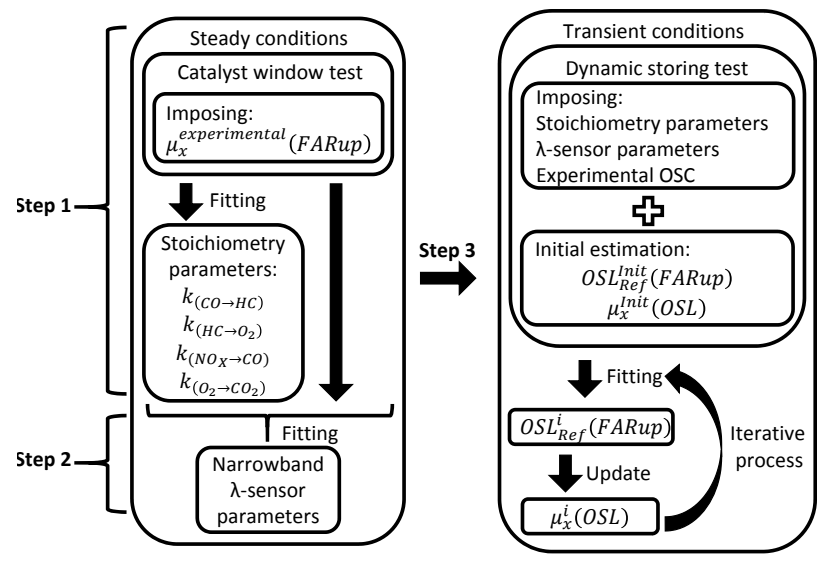

Figure 6. Fitting process diagram.

the parameters obtained are considered valid for any other operating condition, thus no additional iterations are needed. Finally, in order to obtain the curves $O S L_{\text {ref }}(F A R u p)$ and $\mu_{x}(O S L)$ an iterative process is performed in Step 3. This last step allows to fit these curves for a certain operating point, for any other operating conditions the procedure is the same. A summary of all the fitted parameters during this process is listed in table 1 .

Table 1: Model parameters

\begin{tabular}{ccc}
\hline Step & $\begin{array}{c}\text { Number of } \\
\text { parameters }\end{array}$ & Description \\
\hline 1 & 4 & equivalence parameters $\left(k_{x}\right)$ \\
2 & 6 & $\lambda$-sensor parameters \\
3 & 4 & curves $\mu_{x}(O S L)$ \\
3 & 1 & curve $O S L_{r e f}(F A R u p)$ \\
\hline
\end{tabular}

\subsection{Step 1: Chemical stoichiometry, equivalence parameters $k_{x}$}

A specific experimental test has been developed in order to fit the four stoichiometric parameters: $k_{(\mathrm{CO} \rightarrow \mathrm{HC})}, k_{\left(\mathrm{HC} \rightarrow \mathrm{O}_{2}\right)}$, $k_{\left(\mathrm{NO}_{x} \rightarrow \mathrm{CO}\right)}$ and $k_{\left(\mathrm{O}_{2} \rightarrow \mathrm{CO}_{2}\right)}$. From now on, this test will be referred as catalyst window test, an example of this sort of test is shown in figure 7 . The test consist of a simple quasi-steady FAR evolution from rich $(F A R=1.1)$ to lean conditions $(\mathrm{FAR}=0.9)$, the duration between steps is 30 seconds and each one has an amplitude of 0.01 .

When the model is lunched for first time, the curves $\mu_{x}(O S L)$ and $O S L_{r e f}(F A R u p)$ are still unknown. However, it is important to notice that adsorption rates behaves as conversion efficiency rates when all the adsorbed mass reacts. Moreover, TWC dynamics have low impact on the catalyst window test because of being a test consisting of a set of steady state points. Therefore, experimental conversion efficiency curves depending on FAR upstream the catalyst can be imposed, instead of using a more proper (but still unknown in this step) adsorption dependence with OSL $\left(\mu_{x}(O S L)\right)$. In that way, the curve $O S L_{r e f}(F A R u p)$, is still not needed to lunch the model. Following this approach, any non-linear programming solver can be used to fit the equivalence parameter of each species involved by minimizing a certain cost-function. In particular, in this work the root mean square of the prediction of each chemical species has been used.
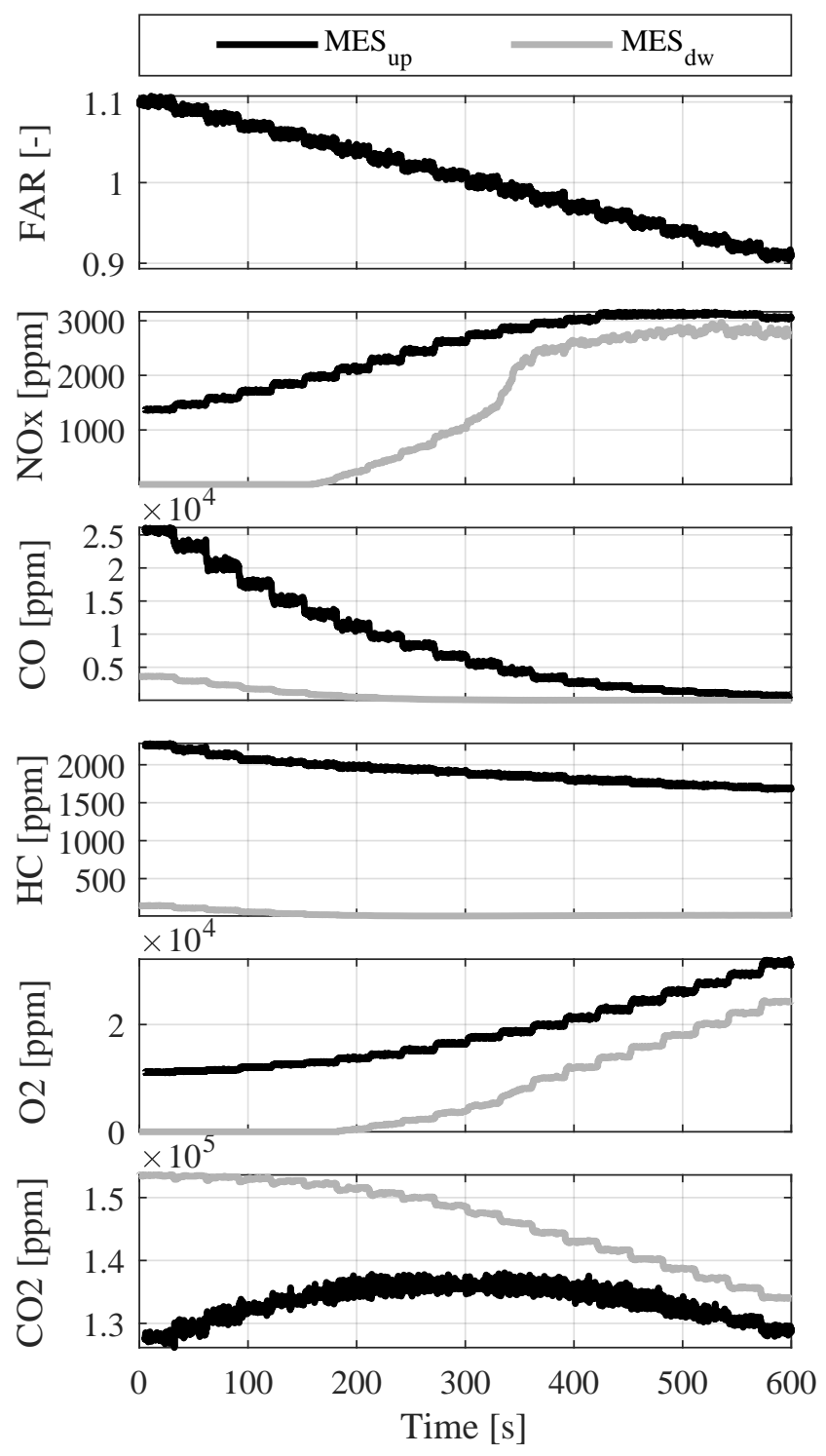

Figure 7. Example of catalyst window test at $1250 \mathrm{rpm}$ and $25 \mathrm{Nm}$ with new TWC. MES ${ }_{\text {up }}$ and $\mathrm{MES}_{\mathrm{dw}}$ represent measurements upstream and downstream of the TWC respectively.

\subsection{Step 2: Downstream narrowband $\lambda$ sensor parameters}

Once obtained the equivalence parameters $\left(k_{x}\right)$, the fitting process of the six parameters used in the downstream narrowband $\lambda$ sensor sub-model is analogous to the previous one. The curves $\mu_{x}(O S L)$ and $O S L_{r e f}(F A R u p)$ are still unknown, thereby experimental conversion efficiency curves depending on FAR upstream the catalyst are imposed again. The only difference is that in this case both TWC model outputs NOx and $\mathrm{CO}$ are the inputs of this sub-model, hence the equivalence parameters $\left(k_{x}\right)$ previously obtained are needed in this step. The proper $\lambda$ sensor parameters will be those that minimize the error between the model estimation of the FAR voltage downstream of the TWC and the actual measurement during the catalyst window test. 


\subsection{Step 3: OSL $L_{r e f}(F A R)$ and $\mu_{x}(O S L)$ calibration}

A reasonable OSC value can be obtained by means of experimental measurements ${ }^{42}$, the typical test lies on FAR steps from rich to lean and vice versa, although there seem not to be too much agreement regarding which one is the best, since each one presents some advantages and disadvantages. According to the available bibliography, some authors ${ }^{1}$ prefer the signal of the switch-type $\lambda$ sensor downstream of the TWC, because its signal is more accurate than the one provided by wideband $\lambda$ sensors, and the transition point that indicates the end of the filling/depleting process is more clear. Also with narrowband $\lambda$ sensors, an alternative method is shown in Miyamoto et al., 2002 ${ }^{43}$, while in Theis, $1996^{44}$ the author ensures that the different OSC obtained when filling and depleting are quite similar except for brick temperatures below 450 degrees. Other authors suggest the use of wideband $\lambda$ sensors, in Balenovic et al., $2002^{25}$ a lean to rich step is performed, since in the opposite case the longer the duration at rich conditions the higher OSC value obtained. However, in Ingram et al., $2003^{45}$ the rich to lean step is proposed, because the error bias of the sensor at lean is smaller than the one at rich conditions, thus the end of the integration is more accurate during the filling process, although the signal sensor correction is needed in both.

In the present work, with the aid of wideband $\lambda$ sensors upstream and downstream the catalyst, the last one properly corrected, the OSC has been measured experimentally by integrating the oxygen stored during the filling process (rich to lean step). The OSC value obtained for the new TWC is 1042 milligrams while for the aged TWC it is 500 milligrams. From this OSC experimentally measured, a preliminary estimation of the curves $O S L_{r e f}(F A R)$ and $\mu_{x}(O S L)$ with $x \equiv\left\{H C, N O_{\mathrm{x}}, C O, O_{2}\right\}$ is needed. The former can be estimated by imposing a linear correlation between FAR upstream TWC and OSL. For example, guessing that the maximum OSL is achieved for the minimum FAR and vice versa. Again considering that adsorption rates behaves as conversion efficiency rates when all the adsorbed mass reacts, a preliminary estimation of the adsorption rate of each species as function of OSL $\left(\mu_{x}(O S L)\right)$ can be obtained. However, experimental conversion efficiency rates are not function of OSL, but function of FAR. Therefore, for the first iteration, the experimental conversion efficiency curves of the catalyst window test as function of FAR upstream TWC can be used as function of OSL by using the previous estimation of the curve $O S L_{r e f}(F A R)$ in order to obtain an estimation of the aforementioned curve $\mu_{x}(O S L)$.

To properly calibrate both curves, an iterative process is proposed (figure 6). In this case, several experimental dynamic tests have been used, as the one shown in figure 8 (hereinafter referred as dynamic storing test). These tests consist of several FAR steps with decreasing period at lean conditions, always between the same upper and lower thresholds in terms of FAR. The idea is to impose progressively shorter filling processes beginning with same depleting level. Then repeating the test for different thresholds to completely sweep the interesting range of

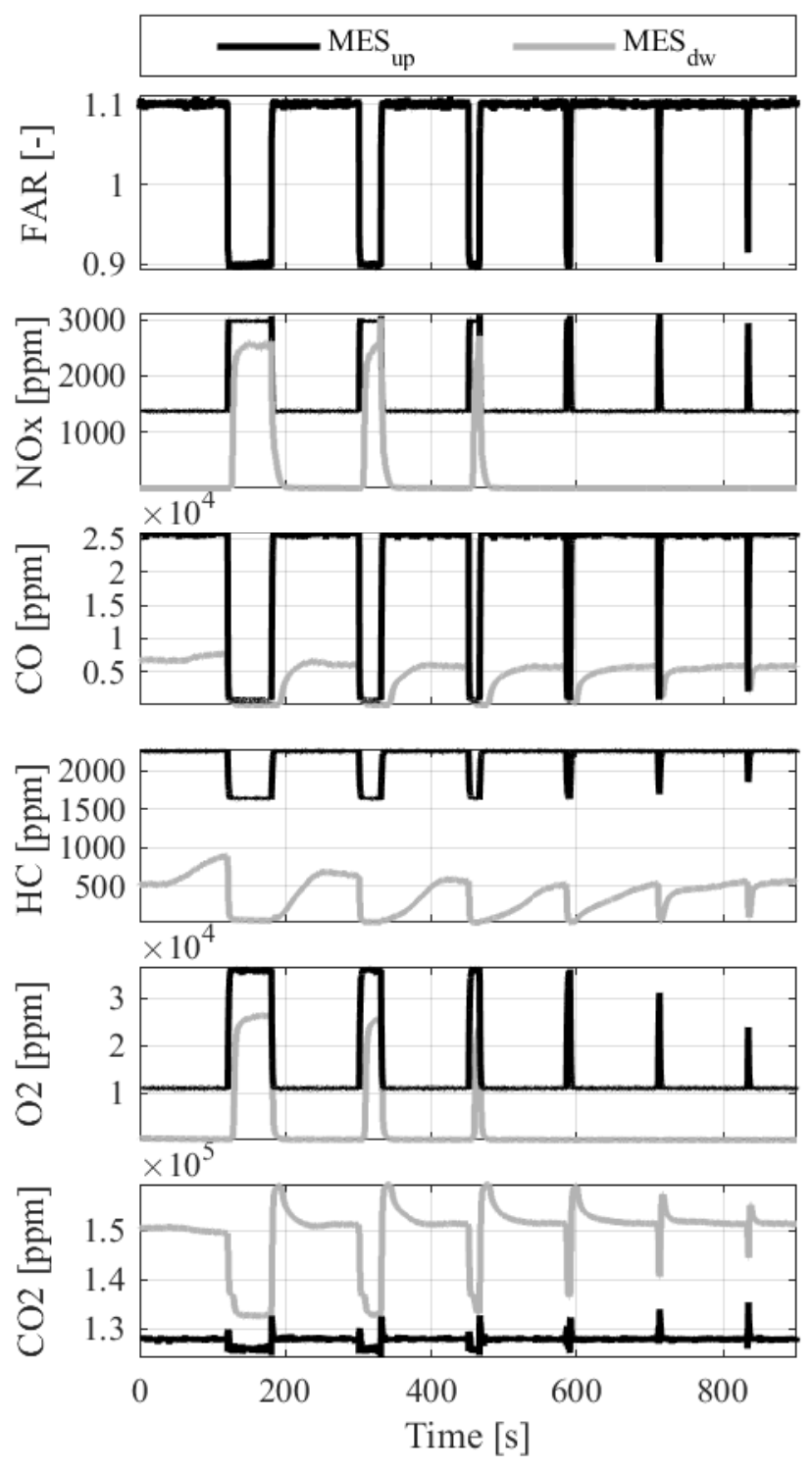

Figure 8. Example of dynamic storing test at $1250 \mathrm{rpm}$ and 25 $N \boldsymbol{m}$ with new TWC. MES $\mathrm{Sp}_{\mathrm{up}}$ and $\mathrm{MES}_{\mathrm{dw}}$ represent measurements upstream and downstream of the TWC respectively.

FAR and OSL. These dynamic storing tests allow to fit properly the curve $O S L_{r e f}(F A R)$ (until now just an initial estimation of this curve had been proposed), which in turn allows to fit the dynamic behaviour of the model. Since the adsorption curves depend on OSL an iterative process can be performed, updating the adsorption curves $\left(\mu_{x}(O S L)\right)$ with the last version of the aforementioned curve $O S L_{r e f}(F A R)$. Finally, this iterative process can be repeated again by using the proposed dynamic storing tests until a good match between model outputs and corresponding measurements is reached. For this step, the cost function must take into account the error in the estimation of at least one oxidizing and one reducing species, for example $\mathrm{NO}_{\mathrm{x}}$ and $\mathrm{CO}$ respectively.

Figure 9 shows the calibration curve $O S L_{r e f}(F A R)$ obtained for the same operating conditions with both the new and the aged catalysts. At very lean conditions the catalyst can be completely filled, however, at rich conditions its capability to store oxygen is almost null as expected. Within 


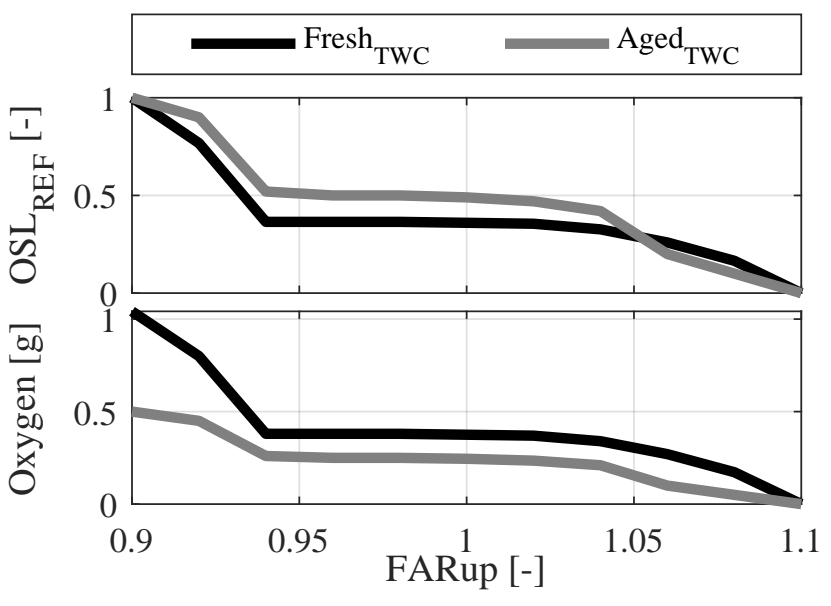

Figure 9. Curve $O S L_{\text {ref }}$ (top) and oxygen stored (bottom) for $1250 \mathrm{rpm}$ and low load $(25 \mathrm{Nm})$ with fresh $\left(\right.$ Fresh $\left._{\mathrm{TWC}}\right)$ and aged $\left(\right.$ Aged $\left._{\mathrm{TWC}}\right)$ converters respectively.

this FAR range, the storing capabilities decrease from lean to rich in a non-linear way, showing a flat plateau around stoichiometric conditions. The shape of these curves is alike, although the ageing level of each catalyst is different, which indicates that the behaviour of both TWC is similar, and the main differences lie in the total OSC as well as in the relative OSL reached for the same exhaust gas composition.

Figure 10 shows the result of the fitting process for the dynamic storing test with the aged TWC at $1250 \mathrm{rpm}$ and low load $(25 \mathrm{Nm})$. The fitting process cannot improve the small discrepancies that this figure shows between model outputs and experimental data. In spite of this, the model represent the dynamics of the TWC in transient phase and allows to quantify the concentration of the main pollutant emissions and the downstream narrowband $\lambda$ sensor reasonably. Therefore, the model could be a good estimator of the oxygen storing level. In the case of $\mathrm{CO}$ and $\mathrm{HC}$, the model dynamics during lean to rich steps is faster than experimental results, which could be due to the lack of longitudinal discretization of the model. To take into account this effect, the number of nodes could be increased since currently the model only accounts for one node. The narrowband $\lambda$ sensor model also fits well with experimental data although a bias error appears at rich conditions, considering the $\mathrm{H}_{2}$ effect on $\lambda$ sensor could solve this issue but increasing also the model complexity.

\subsection{Experimental validation}

Experimental measurements at steady and dynamic conditions of two TWCs with different ageing level have been carried out, for each one, several operating conditions have been assessed. Tables 2 and 3 summarizes the test used to fit and validate the model respectively.
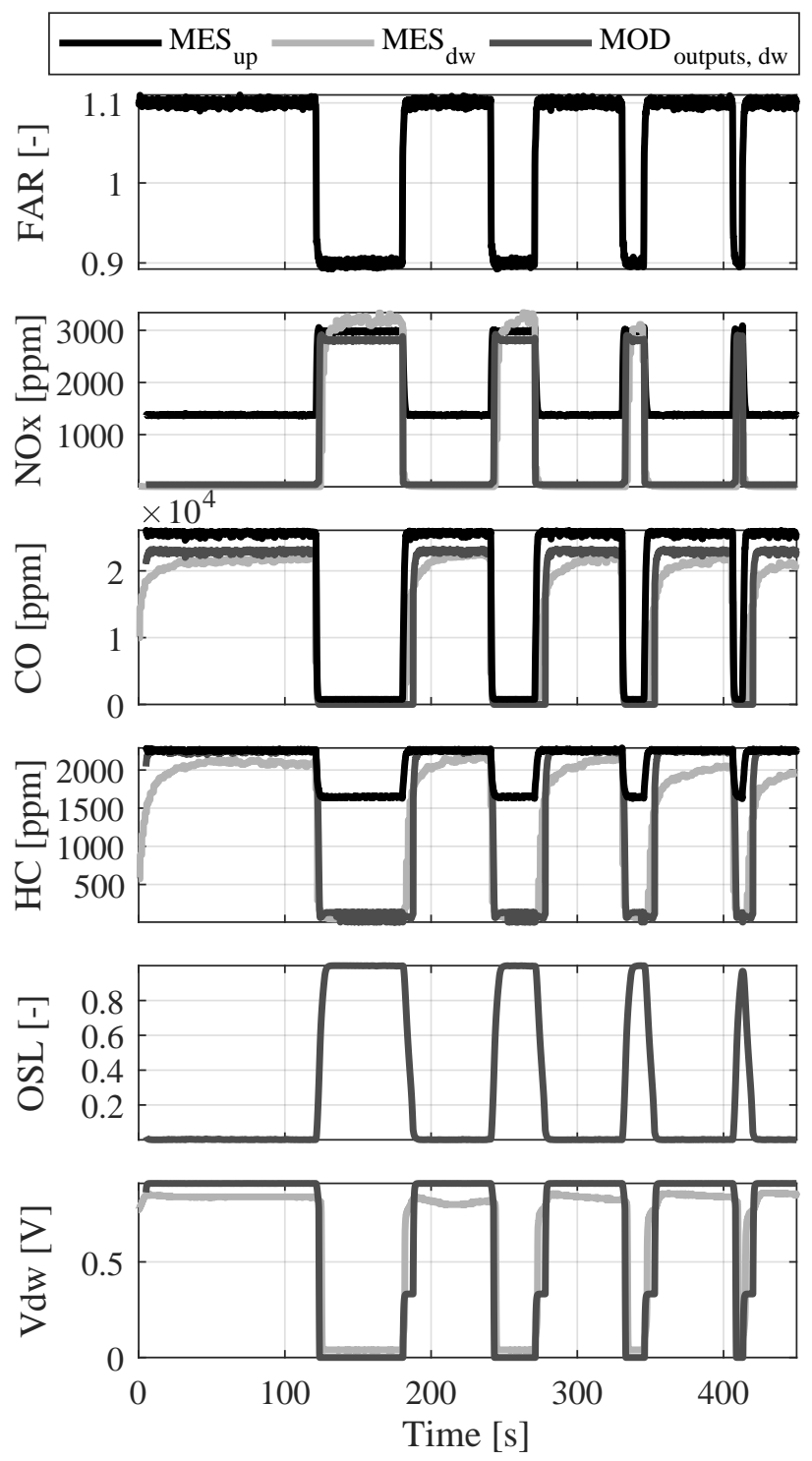

Figure 10. Example of the results obtained with the model fitting process. Dynamic storing test at $1250 \mathrm{rpm}$ and $25 \mathrm{Nm}$ with aged TWC. MES ${ }_{u p}, M S_{d w}$ and $M O D_{\text {outputs,dw }}$ represent measurements upstream of the TWC, measurements downstream of the TWC and model outputs downstream of the TWC respectively.

Table 2: Tests for model fitting

\begin{tabular}{clcc}
\hline Param. & Test & Op. cond. & TWC \\
\hline$k_{x}, \lambda$-sensor & $\begin{array}{l}\text { catalyst } \\
\text { window }\end{array}$ & $1250 \mathrm{rpm}-25 \mathrm{Nm}$ & new \\
$O S L_{r e f}, \mu_{x}$ & $\begin{array}{l}\text { dynamic } \\
\text { storing }\end{array}$ & $1250 \mathrm{rpm}-25 \mathrm{Nm}$ & new \\
$O S L_{r e f}, \mu_{x}$ & $\begin{array}{l}\text { dynamic } \\
\text { storing }\end{array}$ & $1250 \mathrm{rpm}-25 \mathrm{Nm}$ & aged \\
$O S L_{r e f}, \mu_{x}$ & $\begin{array}{l}\text { dynamic } \\
\text { storing } \\
\text { dynamic } \\
\text { storing }\end{array}$ & $2500 \mathrm{rpm}-75 \mathrm{Nm}$ & new \\
$O S L_{r e f}, \mu_{x}$ & & rpm - 75 Nm & aged \\
& &
\end{tabular}

The parameters related with TWC performance at steady state (Steps 1 and 2 of the fitting process in figure 6), that is, the four equivalence parameters $\left(k_{x}\right)$ as well as the six parameters of the narrowband $\lambda$ sensor model, are valid for any operating condition. Of course, OSC must be obtained 
experimentally for the corresponding ageing level of the TWC.

Table 3: Tests for model validation

\begin{tabular}{clcc}
\hline \multicolumn{1}{c}{ Param. } & Test & Op. cond. & TWC \\
\hline$k_{x}, \lambda$-sensor & $\begin{array}{l}\text { catalyst } \\
\text { window }\end{array}$ & $1250 \mathrm{rpm}-25 \mathrm{Nm}$ & aged \\
$k_{x}, \lambda$-sensor & $\begin{array}{l}\text { catalyst } \\
\text { window }\end{array}$ & $2500 \mathrm{rpm}-75 \mathrm{Nm}$ & aged \\
$k_{x}, \lambda$-sensor & $\begin{array}{l}\text { catalyst } \\
\text { window }\end{array}$ & $2500 \mathrm{rpm}-75 \mathrm{Nm}$ & new \\
$O S L_{r e f}, \mu_{x}$ & $\begin{array}{l}\text { random } \\
\text { FAR steps }\end{array}$ & $250 \mathrm{rpm}-25 \mathrm{Nm}$ & new \\
& TWC & $2500 \mathrm{rpm}-75 \mathrm{Nm}$ & aged \\
& purge & &
\end{tabular}

In this regard, figures 11,12 and 13 show the model validation in the catalyst window test for different ageing levels and operating conditions. All of them have been simulated by using exactly the same calibration for equivalence parameters $\left(k_{x}\right)$ and $\lambda$ sensor model, since Step 1 and 2 of the fitting process have been performed by using the catalyst window test at $1250 \mathrm{rpm}$ and low load $(25 \mathrm{Nm})$.

Due to the simplicity of the chemical approach followed in this control-oriented model (remember that water-gas shift and steam-reforming reactions have been neglected), the model outputs show some discrepancies regarding the experimental measurements. These model errors are especially relevant for the new TWC (figure 11) at very rich conditions. The issue lies in the fact that the oxygen demand of a new catalyst is strongly different when comparing rich with lean conditions. Thus if the equivalence parameter for hydrocarbons to equivalent oxygen $\left(k_{\left(\mathrm{HC}_{\mathrm{CO}}\right)}\right)$ is such that it allows to reach the oxygen level needed to fulfil the oxidation capabilities at lean conditions, then the oxygen availability upstream of the catalyst is not enough at rich conditions and vice versa. It happens mainly with the new TWC since the effects of water-gas shift and steamreforming reactions tend to get deactivated with ageing, thus its oxidation capabilities are higher than the ones of the aged catalyst. In this sense, figures 12 and 13 show how the aforementioned issue is almost negligible when an aged catalyst is modelled.

The loss of performance in terms of $\mathrm{NO}_{\mathrm{x}}$ reduction at rich conditions is a behaviour observed experimentally in the aged catalyst that the model is not able to represent. The impact of this effect is small as shown in figure 13, however, this kind of chemical deactivation is not considered in the current model.

Despite these two effects, which appear at very rich conditions, the overall model performances at steady state are good. The main effort has been focused on achieving accurate results around stoichiometric conditions, where the transition between rich and lean behaviour shows up. $\mathrm{NO}_{\mathrm{x}}, \mathrm{CO}$ and $\mathrm{HC}$ estimations are accurate enough for the implementation to which the model is oriented, that is, control purposes. The model reflects properly the FAR range at which the TWC is more active, as shown by the shape of the $\mathrm{CO}_{2}$ curve downstream of the catalyst.

In the same way, the $\lambda$ sensor model is able to predict correctly the catalyst behaviour in spite of the bias error at rich conditions. Due to the strong non-linearity of these sensors, providing an accurate value at steady when the
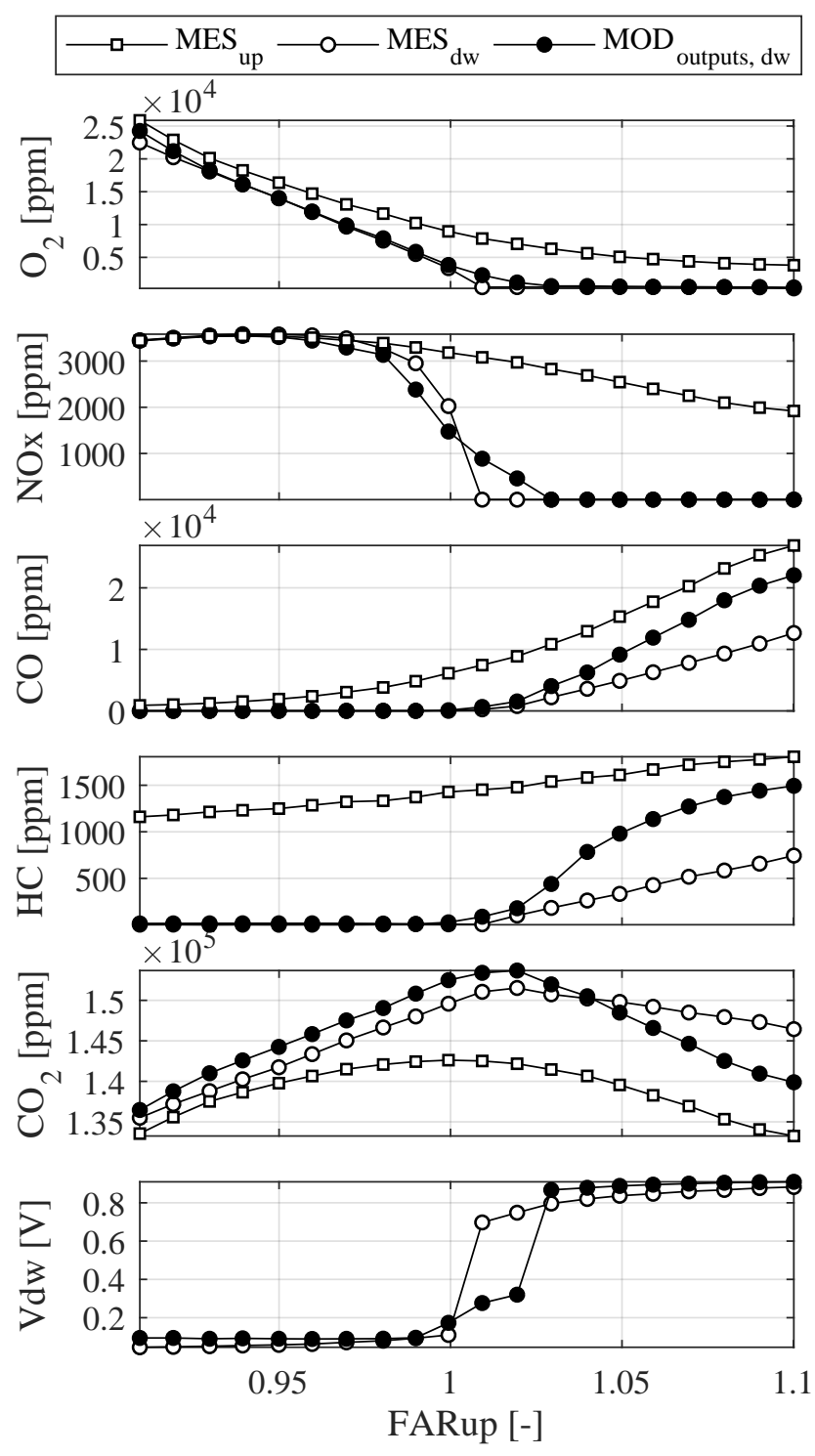

Figure 11. Model validation. Catalyst window test at 2500 rpm and low-mid load (75 Nm) with new TWC. MES ${ }_{\text {up }}$, $M E S_{d w}$ and $M O D_{\text {outputs,dw }}$ represent measurements upstream of the TWC, measurements downstream of the TWC and model outputs downstream of the TWC respectively.

sensor is in the switching range is really difficult, but the key lies in the fact that the model reflect properly the FAR where the transition happens, since it is fed with $\mathrm{NO}_{\mathrm{x}}$ and $\mathrm{CO}$ outputs.

Figures 14 and 15 show, for each species, the error distribution at steady state, that is, the percentage of samples with an error below a certain threshold for lean and rich range respectively. $\mathrm{CO}_{2}$ and $\mathrm{O}_{2}$ errors, unlike the rest, are expressed in relative terms, since these species do no reach values near zero ppm at any FAR, with the only exception of $\mathrm{O}_{2}$ at very rich conditions. The main differences between lean and rich conditions are given for reducing species, mainly because of the aforementioned calibration problems at rich conditions with the new TWC. The rest of parameters behaves in a similar way for all FAR tested.

Regarding the dynamic performance of the catalyst model, two different test have been developed to validate it. Figure 16 compares the model outputs with the data obtained in 

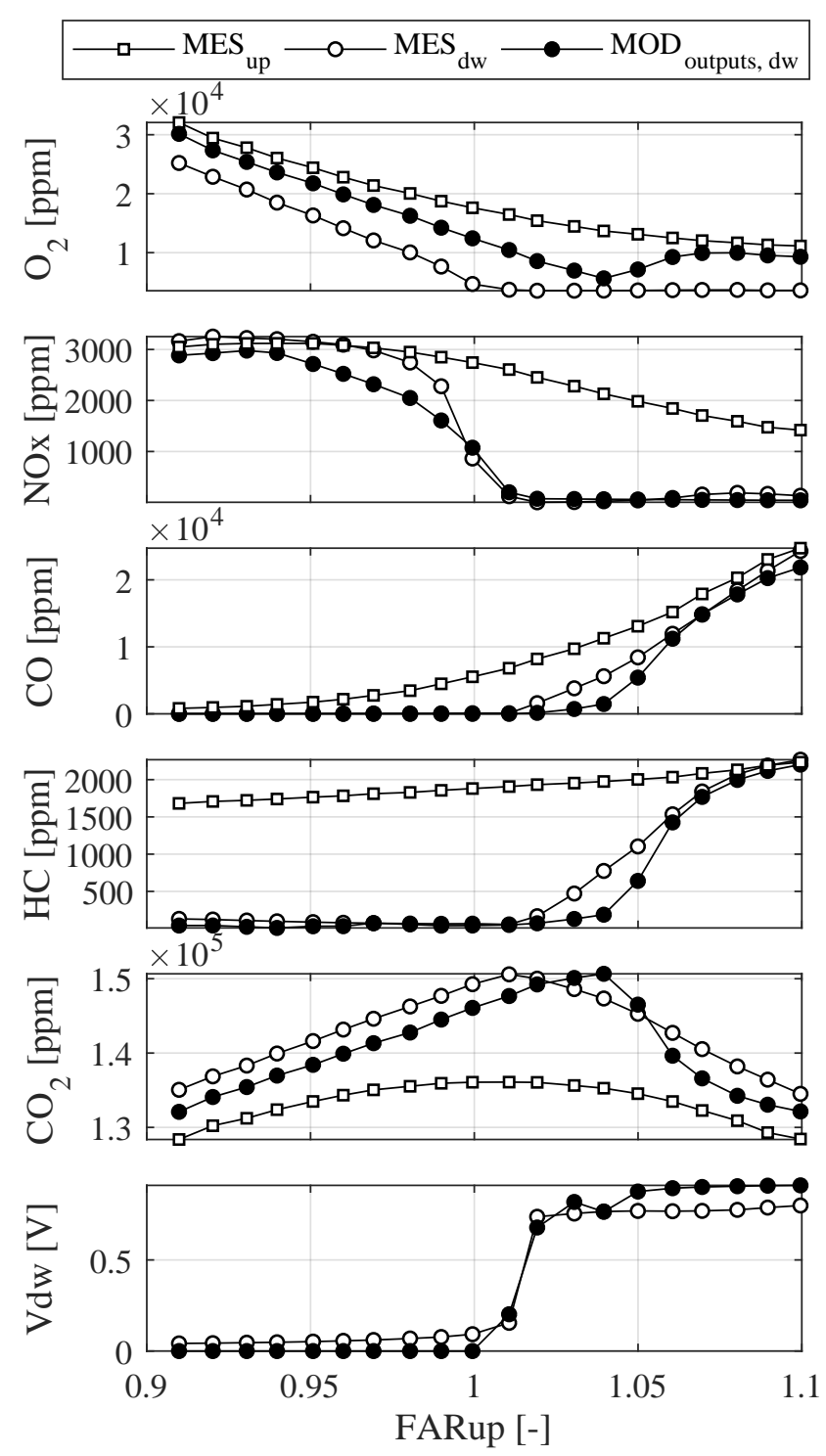

Figure 12. Model validation. Catalyst window test at 1250 rpm and low load $\left(25 \mathrm{Nm}\right.$ ) with aged TWC. MES ${ }_{\mathrm{up}}, \mathrm{MES}_{\mathrm{dw}}$ and $M O D_{\text {outputs, dw }}$ represent measurements upstream of the TWC, measurements downstream of the TWC and model outputs downstream of the TWC respectively.

an experimental test with the new TWC, in which pseudorandom FAR steps at low engine speed and load have been measured. This test reflects the potential of the model to aid in emissions control strategies, since it provides key information about the catalyst state, as well as on the margin available to correct a certain FAR disturbance in time and quantifying the emissions penalty. The OSL together with the $\lambda$ sensor estimations allow to distinguish perfectly between tolerable and unacceptable FAR steps.

Figure 17 shows a zoomed view of the same test. At the beginning, the system is working at lean conditions with an OSL around 1 until the moment at which a significant step towards rich is performed. Then, $\mathrm{NO}_{\mathrm{x}}$ emissions drop almost immediately while $\mathrm{CO}$ and $\mathrm{HC}$ remain low despite their increasing inlet values. The OSL shows a fast transition followed by another much slower. Just when the last one reaches steady conditions, $\mathrm{NO}_{\mathrm{x}}$ and $\mathrm{CO}$ emissions reach also their respective steady values and, as a consequence, the
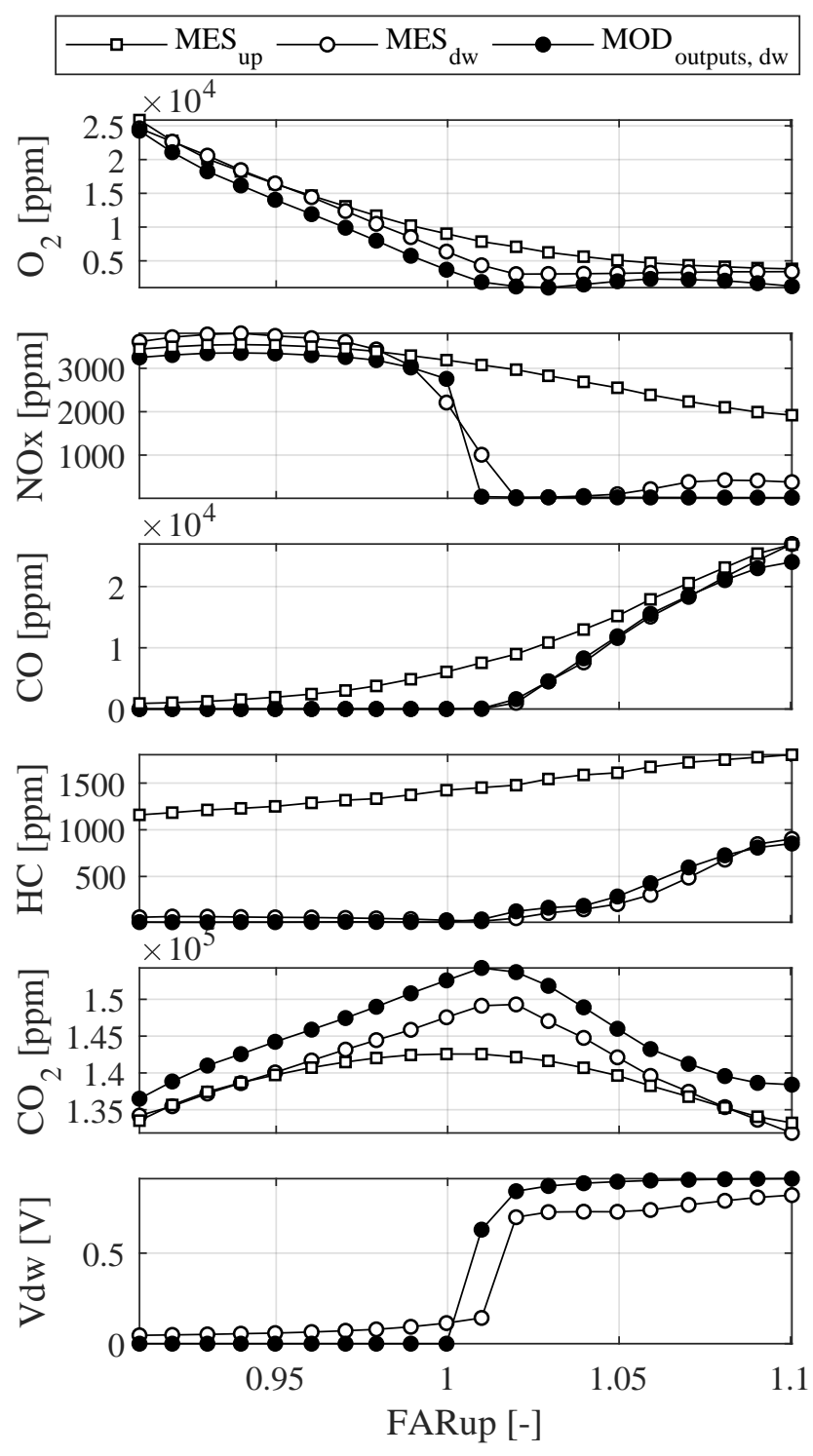

Figure 13. Model validation. Catalyst window test at 2500 rpm and low-mid load (75 Nm) with aged TWC. MES ${ }_{\text {up }}$, $M S_{d w}$ and $M O D_{\text {outputs,dw }}$ represent measurements upstream of the TWC, measurements downstream of the TWC and model outputs downstream of the TWC respectively.

switch-type $\lambda$ sensor voltage increases strongly. After that, the additional rich and lean steps of lower amplitude do not affect in a remarkable way the OSL, as it happens with CO and $\mathrm{HC}$ emissions. However, these FAR steps are strongly reflected on $\mathrm{NO}_{\mathrm{x}}$ emissions because of the lack of excess $\mathrm{CO}$.

Figure 18 shows the temperature evolution during the same test. The impact of FAR steps on inlet temperature is rather limited, hence it is almost constant around 380 ${ }^{\circ} \mathrm{C}$ during the whole test. However, brick temperature is markedly affected by FAR evolution in both average and peak values regarding inlet values. The exothermic reactions tend to increase the average value since a certain amount of $\mathrm{HC}$ and $\mathrm{CO}$ is always being oxidized whatever the inlet FAR. In turn, oxygen storing involves temperature pulses during FAR transients, as a consequence of the simultaneous availability of reducing and oxidizing species in significant amounts. Finally, the outlet gas temperature follows the 

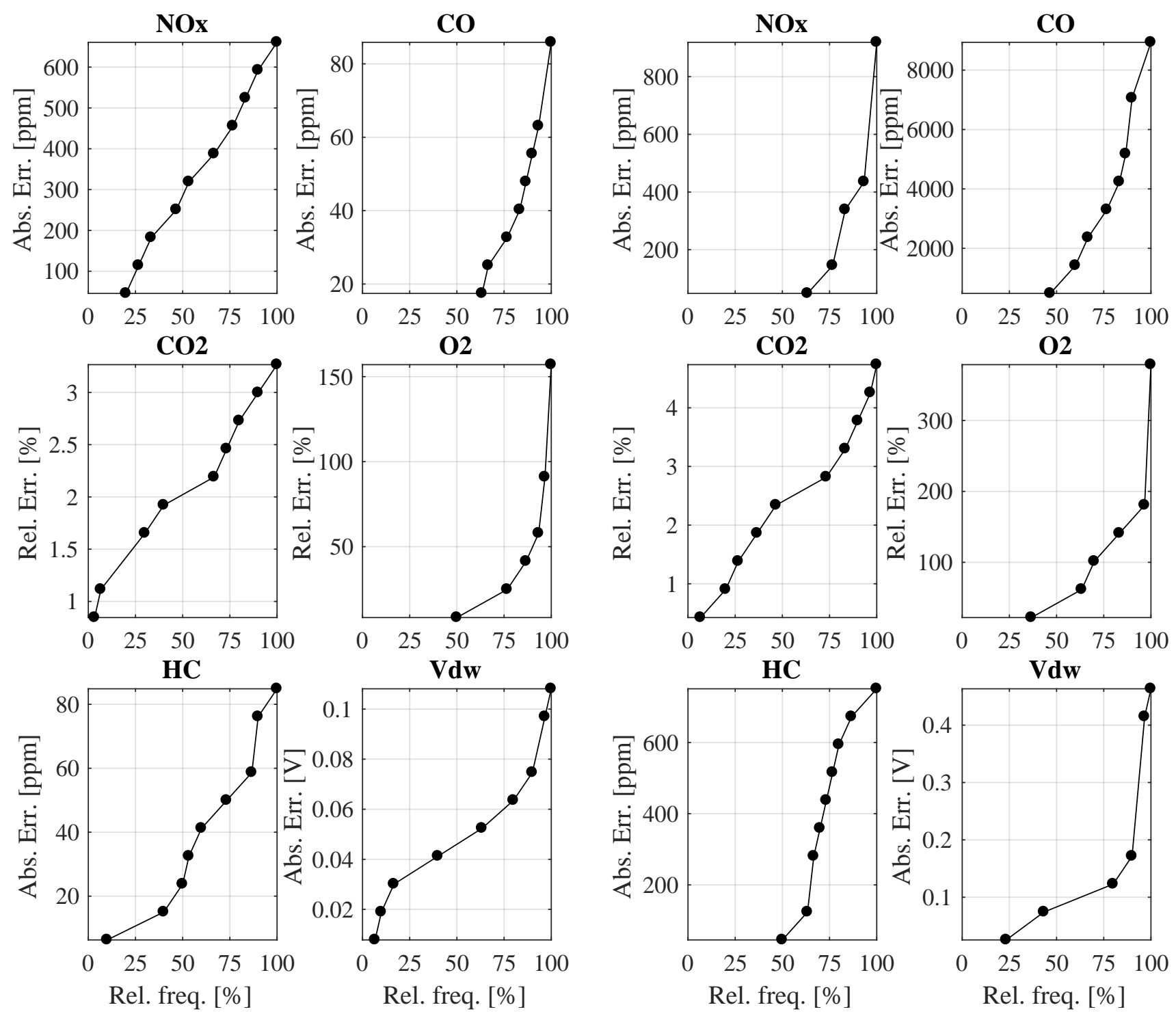

Figure 14. Model validation. Error metrics for lean range at steady conditons. $\mathrm{X}$-axis represent the cumulative relative frequency. Y-axis represent the error between measurements and model outputs at catalyst outlet, in terms of absolute error for top and bottom rows as well as in terms of relative error for mid row.

dynamic evolution imposed by brick temperature, but with reduced average values and amplitude oscillations due to heat losses to the environment as well as to the restricted residence time of the gas inside the TWC. The model is able to predict the overall behaviour although in some cases it overestimates or underestimates the actual temperature peaks. This lack of accuracy on temperature prediction is not crucial for the present approach, inasmuch as the temperature effect on catalyst performance is secondary in comparison with oxygen storing and inlet gas composition, at least for conditions above light-off temperature.

On the other hand, figure 19 shows a quite more specific test, in which the engine is running without fuel injection at constant speed during 10 seconds and after that, the nominal conditions (2500 rpm and $75 \mathrm{Nm})$ are reached again. The duration of the injection cut-off chosen is such that it allows to totally fill with oxygen the aged catalyst but does not have an important impact on brick temperature, keeping the TWC

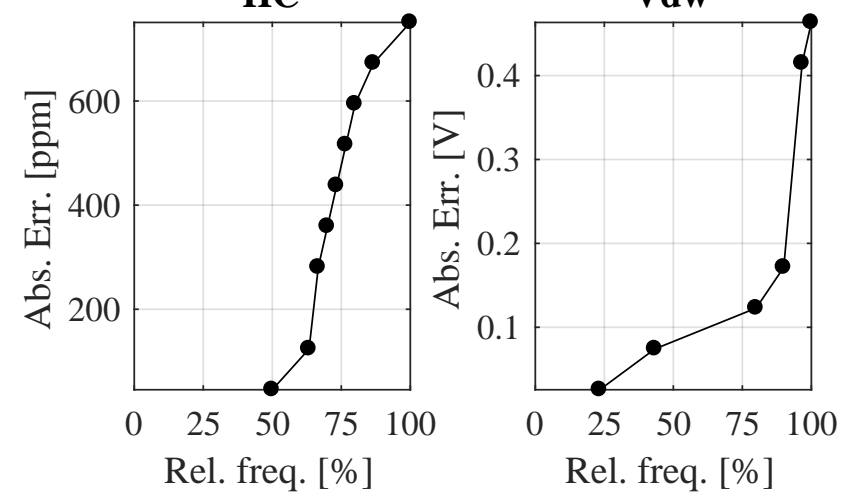

Figure 15. Model validation. Error metrics for rich range at steady conditons. $X$-axis represent the cumulative relative frequency. Y-axis represent the error between measurements and model outputs at catalyst outlet, in terms of absolute error for top and bottom rows as well as in terms of relative error for mid row.

always above the light-off temperature. At the beginning of the test the catalyst is totally filled with oxygen, thus OSL is equal to 1 , the sensor voltage is almost 0 volts and the concentration of all the species are zero since there is no combustion. When the FAR step upstream is performed, a transient phase starts and the TWC is partially purged until reaching nominal conditions, from OSL equal to 1 to OSL around 0.4. Although the switching from injection cutoff to normal combustion is almost instantaneous in terms of TWC dynamics (particularly, the switching duration is equal to one engine cycle), the FAR controller needs some additional time until reaching accurately the target FAR. This situation together with the fact that the catalyst is totally filled of oxygen causes the $\mathrm{NO}_{\mathrm{x}}$ penalty shown in figure 19 . The TWC model is able to capture this behaviour as well as the subsequent delay that shows up until getting steady conditions, when $\mathrm{CO}$ and $\mathrm{HC}$ emissions increase slightly. However, according to the experimental data, this delay is 

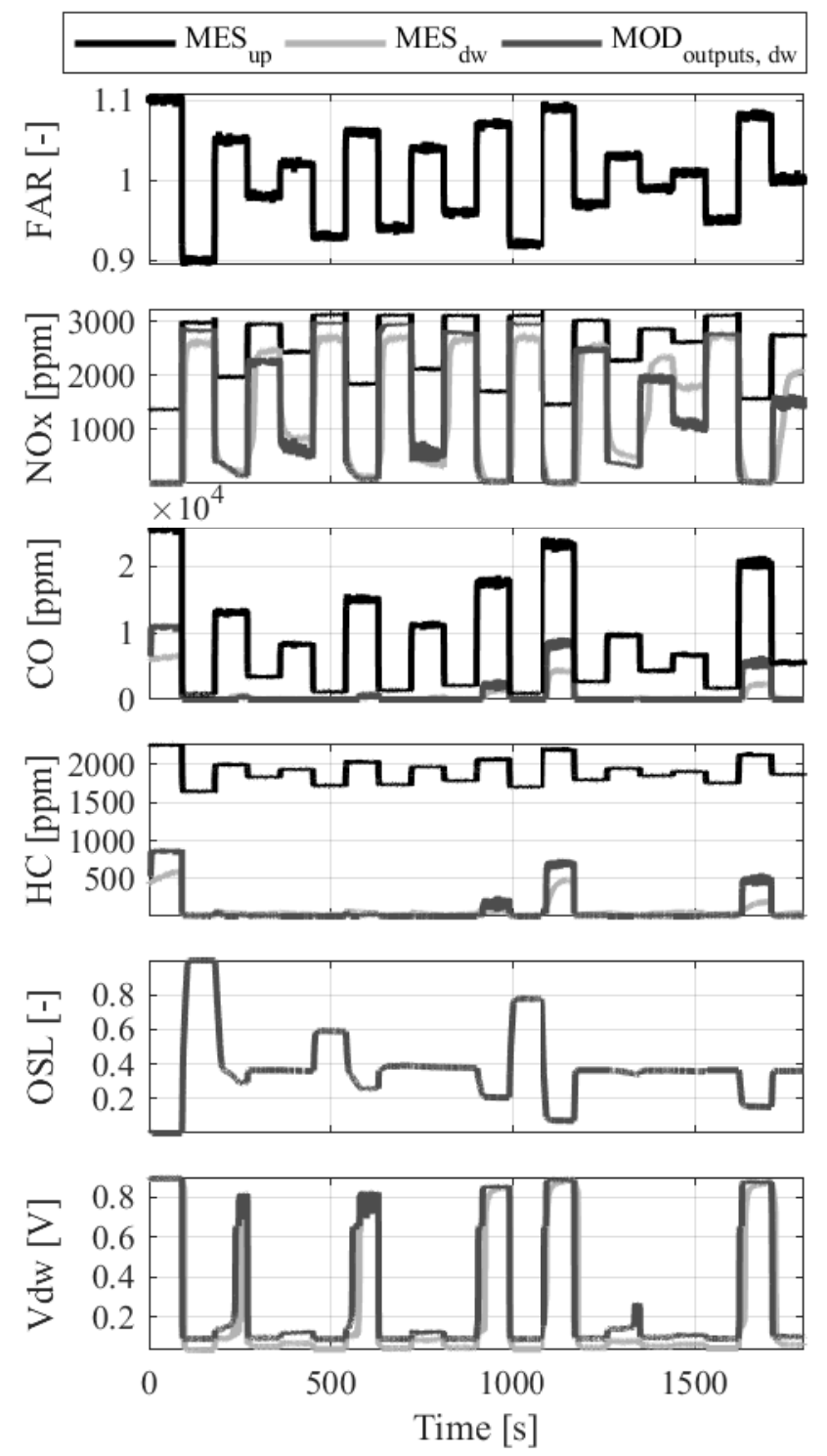

Figure 16. Model validation. Pseudo-random FAR evolution test at $1250 \mathrm{rpm}$ and low load (25 Nm) using the new TWC. $M S_{\text {up }}, M S_{d w}$ and MOD outputs,dw represent measurements upstream of the TWC, measurements downstream of the TWC and model outputs downstream of the TWC respectively.

even greater than the one provided by the model. It is evident seeing the difference between the narrowband $\lambda$ sensor model output and the corresponding measurement (while the model considers that the transient phase lasts 20 seconds, according to the measurements the duration is around 30 seconds). The reason of this discrepancy could be the OSC underestimation or the zero-dimensionality of the model, which could be solved by using a quasi-dimensional model with the aid of additional nodes longitudinally distributed along the catalyst axis. In any case, from a practical point of view, a TWC purging strategy based on this model would be to err on the side of safety.

\section{Summary and conclusions}

A control-oriented model to deal with after-treatment systems based on TWC has been developed. The overall model consist of three parts, the upstream feed gas sub-model, the TWC model itself and the downstream

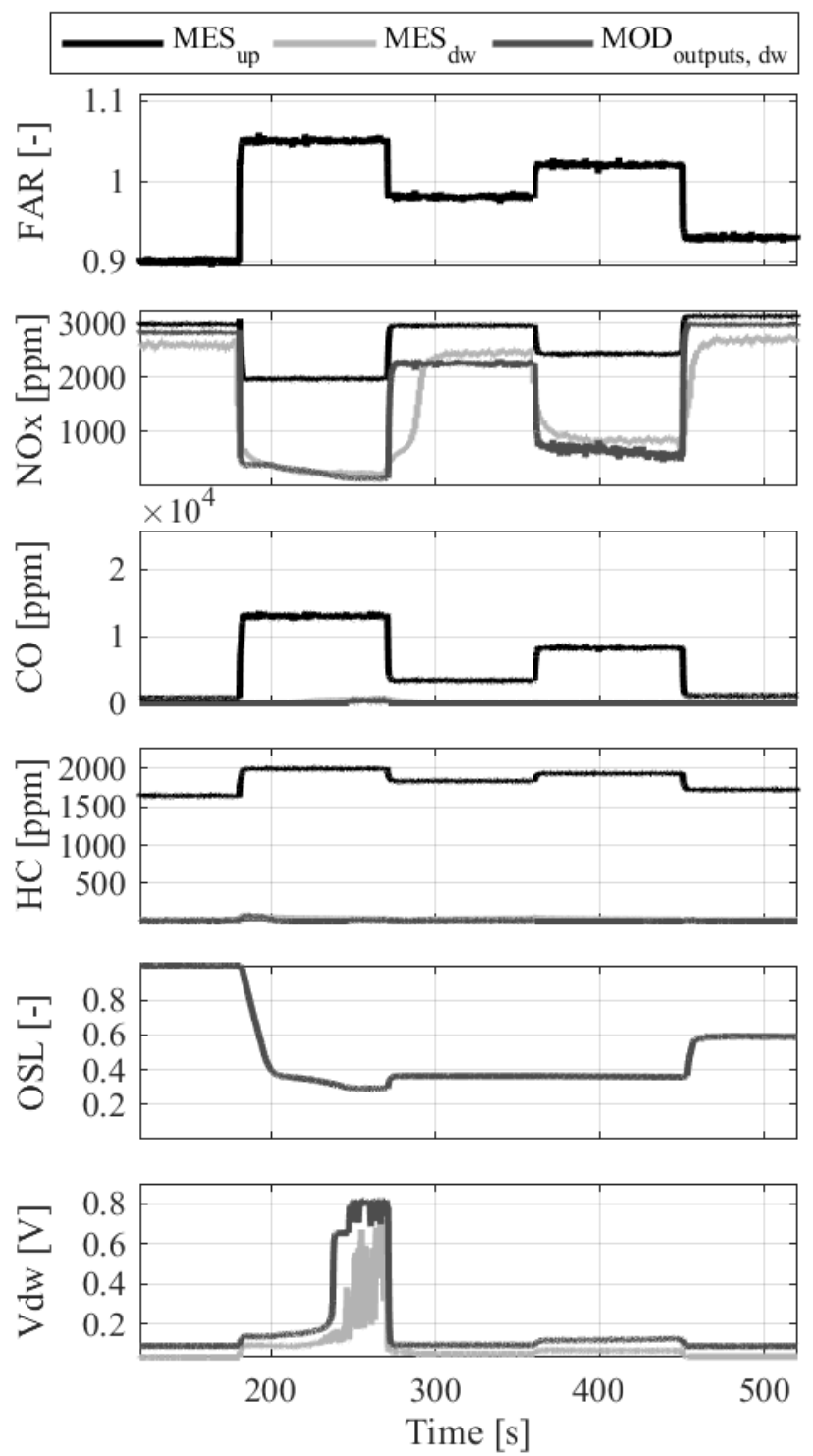

Figure 17. Model validation. Zoomed view of pseudo-random FAR evolution test at $1250 \mathrm{rpm}$ and low load (25 Nm) with new TWC. MES ${ }_{\text {up }}, M S_{\text {dw }}$ and $M O D_{\text {outputs }, \mathrm{dw}}$ represent measurements upstream of the TWC, measurements downstream of the TWC and model outputs downstream of the TWC respectively.

narrowband $\lambda$ sensor sub-model. The present approach is based on the following features: zero-dimensional (just 1 node), lumped-parameter kinetics, real-time capable and able to provide reasonable estimations of OSL, brick temperature, $\lambda$ sensor voltage as well as the main chemical species involved at TWC outlet. Of course this approach implies some limitations, such as the inability to deal with complex behaviours as $\mathrm{NO}_{\mathrm{x}}$ reduction deactivation at very rich conditions with aged TWCs, or the lack of accuracy at very rich conditions with new catalysts. However, in most usual driving conditions it is fully functional and provides useful information regarding the TWC state.

In this sense, the OSL is considered a good indicator of the catalyst state but it cannot be directly measured on-board. Therefore, the model can be used for control purposes since it provides a real-time estimation of the OSL. In particular, during transient phases such as catalyst oxygen purging, where the fuel-to-air ratio can be controlled with the aid of 


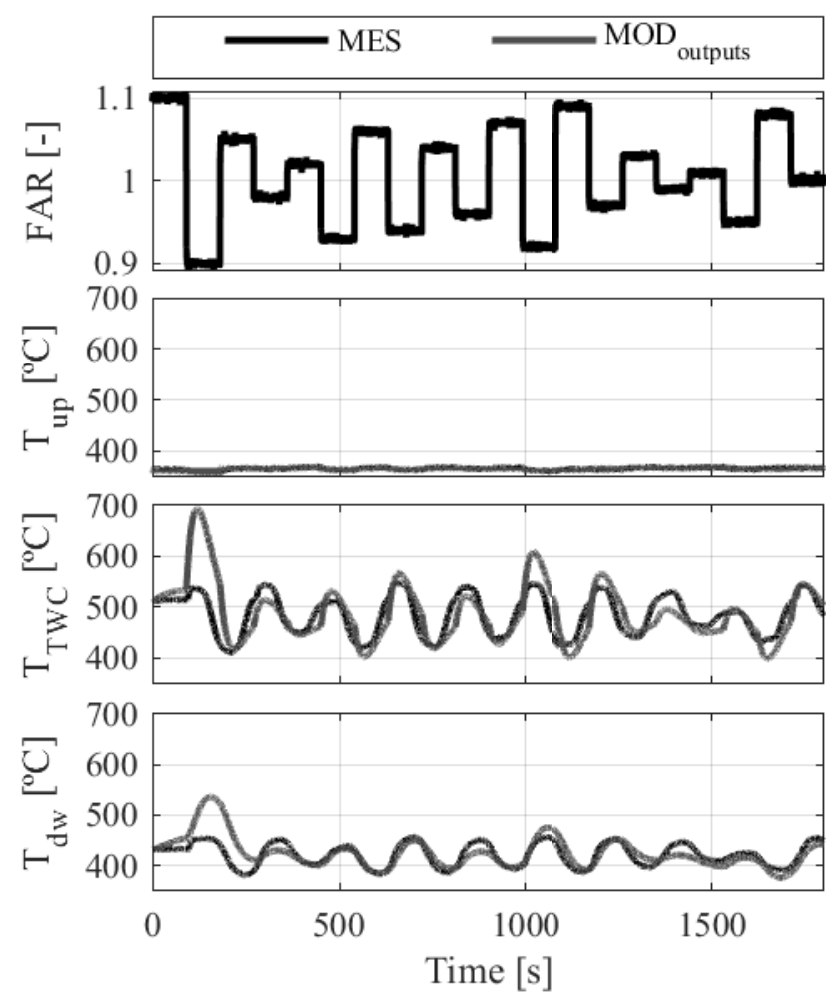

Figure 18. Model validation. Temperatures in pseudo-random FAR evolution test at $1250 \mathrm{rpm}$ and low load (25 Nm) using the new TWC. MES and MOD $D_{\text {outputs }}$ represent measurements and model outputs respectively.

the $\lambda$ sensor feedback but also taking into account the oxygen stored in the TWC by using the information provided by the model.

Moreover, the catalyst ageing reduces the OSC, which in turn induces a faster response of the downstream $\lambda$ sensor after a step from rich to lean conditions or vice versa. That is, for a certain operating point the elapsed time since a step is done upstream of the TWC until it is measured by the downstream $\lambda$ sensor depends mainly on the OSC. Therefore, the modelled $\lambda$ sensor voltage can be compared with the on-board measurement downstream of the catalyst in order to obtain information regarding the TWC ageing level.

\section{Appendix: Nomenclature}

\begin{tabular}{ll} 
Subscripts & \\
\hline$a d s$ & $\begin{array}{l}\text { species adsorbed on the converter } \\
\text { surface } \\
\text { properties or measurements down- } \\
\text { stream TWC } \\
\text { environment heat } \\
\text { equivalent species }\end{array}$ \\
$E N V$ & $\begin{array}{l}\text { species in gas phase } \\
e q\end{array}$ \\
$G P$ & $\begin{array}{l}\text { inlet flow heat } \\
\text { oxidation heat }\end{array}$ \\
$O X$ & reference values \\
$r e f$ & species adsorbed in solid phase \\
$S P$ & portion of oxygen stored in ceria in \\
$S P-C E R I A$ & solid phase \\
$S P-N M$ & portion of oxygen adsorbed in noble \\
& metal in solid phase
\end{tabular}
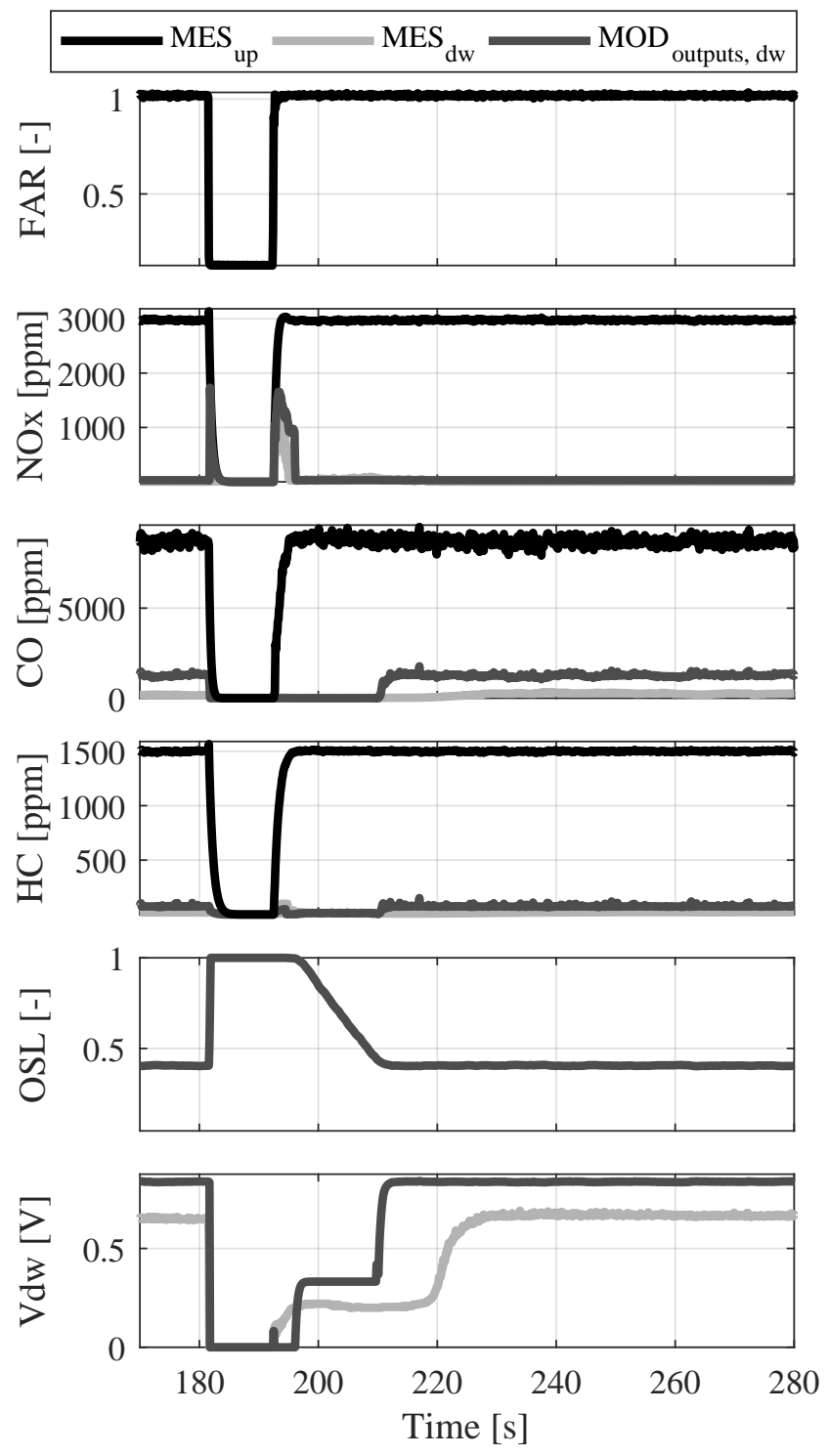

Figure 19. Model validation. Catalyst purge test after injection cut-off at $2500 \mathrm{rpm}$ and low-mid load (75 Nm) with aged TWC. $M E S_{u p}, M E S_{d w}$ and MOD outputs, dw represent measurements upstream of the TWC, measurements downstream of the TWC and model outputs downstream of the TWC respectively.

\begin{tabular}{ll}
\multicolumn{2}{l}{ Subscripts } \\
\hline$T P$ & tailpipe heat \\
$T W C$ & three-way catalyst heat \\
$u p$ & properties or measurements upstream \\
& TWC
\end{tabular}

Parameters

\begin{tabular}{|c|c|c|}
\hline & [\%] & engine load \\
\hline$F A R$ & {$[-]$} & fuel-to-air equivalence ratio \\
\hline$k_{x}$ & {$[-]$} & equivalence parameter of species $x$ \\
\hline$m_{x}$ & {$[g]$} & mass of species $x$ \\
\hline$\mu_{x}$ & {$[-]$} & $\begin{array}{l}\text { relative adsorption coefficient of } \\
\text { species } x\end{array}$ \\
\hline$n$ & {$[r p m]$} & engine speed \\
\hline$O S L$ & {$[-]$} & relative oxygen storing level \\
\hline$\Phi_{L E A N}$ & {$[V]$} & $\begin{array}{l}\text { non-linear function that accounts } \\
\text { for the contribution of oxidizing } \\
\text { species to the voltage provided by } \\
\text { the downstream } \lambda \text { sensor model }\end{array}$ \\
\hline
\end{tabular}




\begin{tabular}{lll}
\multicolumn{2}{l}{ Parameters } \\
\hline$\Phi_{R I C H}[V]$ & $\begin{array}{l}\text { non-linear function that accounts } \\
\text { for the contribution of reducing } \\
\text { species to the voltage provided by } \\
\text { the downstream } \lambda \text { sensor model }\end{array}$ \\
$Q$ & {$[J]$} & $\begin{array}{l}\text { heat } \\
\text { output voltage provided by the } \\
\text { downstream } \lambda \text { sensor model }\end{array}$
\end{tabular}

\section{Funding}

The authors acknowledge the support of Spanish Ministerio de Economía, Industria y Competitividad through project TRA2016-78717-R.

\section{References}

1. Auckenthaler TS, Onder $\mathrm{CH}$ and Geering HP. Aspects of dynamic three-way catalyst behaviour including oxygen storage. IFAC Proceedings Volumes 2004; 37(22): 331-336.

2. Auckenthaler TS, Onder CH and Geering HP. Modelling of a solid-electrolyte oxygen sensor. Technical Report (No. 200201-1293), SAE Technical Paper, 2002.

3. Yang H, Shu G, Tian H et al. Optimization of thermoelectric generator (teg) integrated with three-way catalytic converter (twc) for harvesting engines exhaust waste heat. Applied Thermal Engineering 2018; 144: 628-638.

4. Irwin K, Douglas R, Stewart JD et al. Modelling the variation in precious metal dispersion in a three way catalytic converter after aging. Technical Report (No. 2018-01-0959), SAE Technical Paper, 2018.

5. Koltsakis G, Konstantinidis P and Stamatelos A. Development and application range of mathematical models for 3-way catalytic converters. Applied Catalysis B: Environmental 1997; 12(2-3): 161-191.

6. Zygourakis K. Transient operation of monolith catalytic converters: a two-dimensional reactor model and the effects of radially nonuniform flow distributions. Chemical Engineering Science 1989; 44(9): 2075-2086.

7. Braun J, Hauber $\mathrm{T}$, Többen $\mathrm{H}$ et al. Three-dimensional simulation of the transient behavior of a three-way catalytic converter. Technical Report No. 2002-01-0065, SAE Technical Paper, 2002.

8. Chen DK, Bissett EJ, Oh SH et al. A three-dimensional model for the analysis of transient thermal and conversion characteristics of monolithic catalytic converters. SAE transactions 1988; : 177-189.

9. Byrne H and Norbury J. Mathematical modelling of catalytic converters. Mathematical engineering in industry 1993; 4(1): 27-48.

10. Baba N, Ohsawa K and Sugiura S. Numerical approach for improving the conversion characteristics of exhaust catalysts under warming-up condition. Technical Report No. 962076, SAE Technical Paper, 1996.

11. Konstantas G and Stamatelos A. Modelling three-way catalytic converters: an effort to predict the effect of precious metal loading. Proceedings of the Institution of Mechanical Engineers, Part D: Journal of Automobile Engineering 2007; 221(3): 355-373.

12. Pontikakis G, Konstantas G and Stamatelos A. Threeway catalytic converter modeling as a modern engineering design tool. Journal of Engineering for Gas Turbines and Power(Transactions of the ASME) 2004; 126(4): 906-923.

13. Kumar $\mathrm{P}, \mathrm{Gu} \mathrm{T}$, Grigoriadis $\mathrm{K}$ et al. Spatio-temporal dynamics of oxygen storage and release in a three-way catalytic converter. Chemical Engineering Science 2014; 111: 180-190.

14. Balenovic M, Hoebink J, Backx A et al. Modeling of an automotive exhaust gas converter at low temperatures aiming at control application. Technical Report (No. 1999-01-3623), SAE Technical Paper, 1999.

15. Germann HJ, Onder $\mathrm{CH}$ and Geering HP. Fast gas concentration measurements for model validation of catalytic converters. Technical Report (No. 950477), SAE Technical Paper, 1995.

16. Auckenthaler TS, Onder $\mathrm{CH}$, Geering $\mathrm{HP}$ et al. Modeling of a three-way catalytic converter with respect to fast transients of $\lambda$-sensor relevant exhaust gas components. Industrial \& engineering chemistry research 2004; 43(16): 4780-4788.

17. Nievergeld A, Selow E, Hoebink J et al. Simulation of a catalytic converter of automotive exhaust gas under dynamic conditions. Studies in surface science and catalysis 1997; 109: 449-458.

18. Harmsen JMA. Kinetic modelling of the dynamic behaviour of an automotive three-way catalyst under cold-start conditions. $\mathrm{PhD}$ Thesis, Technische Universiteit Eindhoven, Eindhoven, The Netherlands, 2001.

19. Oh SH and Cavendish JC. Transients of monolithic catalytic converters. response to step changes in feedstream temperature as related to controlling automobile emissions. Industrial \& Engineering Chemistry Product Research and Development 1982; 21(1): 29-37.

20. Chan $S$ and Hoang D. Heat transfer and chemical reactions in exhaust system of a cold-start engine. International journal of heat and mass transfer 1999; 42(22): 4165-4183.

21. Sabatini S, Gelmini S, Hoffman MA et al. Design and experimental validation of a physics-based oxygen storagethermal model for three way catalyst including aging. Control Engineering Practice 2017; 68: 89-101.

22. Schürholz K, Brückner D, Gresser M et al. Modeling of the three-way catalytic converter by recurrent neural networks. IFAC-PapersOnLine 2018; 51(15): 742-747.

23. Brandt EP, Wang Y and Grizzle JW. Dynamic modeling of a three-way catalyst for si engine exhaust emission control. IEEE Transactions on control systems technology 2000; 8(5): 767776.

24. Balenovic M, Backx A and Hoebink J. On a model-based control of a three-way catalytic converter. Technical Report (No. 2001-01-0937), SAE Technical Paper, 2001.

25. Balenovic M, Backx T and De Bie T. Development of a modelbased controller for a three-way catalytic converter. Technical Report (No. 2002-01-0475), SAE Technical Paper, 2002.

26. Shafai $E$, Roduner $C$ and Geering HP. Indirect adaptive control of a three-way catalyst. Technical Report (No. 961038), SAE Technical Paper, 1996.

27. Gonatas E and Stobart R. Prediction of gas concentrations in a three-way catalyst for on-board diagnostic applications. Technical Report No. 2005-01-0054, SAE Technical Paper, 2005.

28. Shaw II BT, Fischer GD and Hedrick JK. A simplified coldstart catalyst thermal model to reduce hydrocarbon emissions. IFAC Proceedings Volumes 2002; 35(1): 307-312. 
29. Bickel J, Odendall B, Eigenberger G et al. Oxygen storage dominated three-way catalyst modeling for fresh catalysts. Chemical Engineering Science 2017; 160: 34-53.

30. Sanketi PR, Zavala JC, Hedrick J et al. A simplified catalytic converter model for automotive coldstart applications with adaptive parameter fitting. In 8th International Symposium on Advanced Vehicle Control, Taipei, Taiwan.

31. Pattas K, Stamatelos A, Pistikopoulos P et al. Transient modeling of 3-way catalytic converters. Technical Report (No. 940934), SAE Technical Paper, 1994.

32. Kiwitz P, Onder C and Guzzella L. Control-oriented modeling of a three-way catalytic converter with observation of the relative oxygen level profile. Journal of Process Control 2012; 22(6): 984-994.

33. Kumar P, Makki I, Kerns J et al. A low-dimensional model for describing the oxygen storage capacity and transient behavior of a three-way catalytic converter. Chemical engineering science 2012; 73: 373-387.

34. Auckenthaler TS, Onder CH and Geering HP. Online estimation of the oxygen storage level of a three-way catalyst. Technical Report (No. 2004-01-0525), SAE Technical Paper, 2004.

35. Gong J, Wang D, Li J et al. Dynamic oxygen storage modeling in a three-way catalyst for natural gas engines: A dual-site and shrinking-core diffusion approach. Applied Catalysis B: Environmental 2017; 203: 936-945.

36. Ramanathan $\mathrm{K}$ and Sharma CS. Kinetic parameters estimation for three way catalyst modeling. Industrial \& Engineering Chemistry Research 2011; 50(17): 9960-9979.

37. Olsson L and Andersson B. Kinetic modelling in automotive catalysis. Topics in catalysis 2004; 28(1-4): 89-98.

38. Möller R, Votsmeier M, Onder C et al. Is oxygen storage in three-way catalysts an equilibrium controlled process? Applied Catalysis B: Environmental 2009; 91(1): 30-38.

39. Rink J, Meister N, Herbst F et al. Oxygen storage in three-waycatalysts is an equilibrium controlled process: Experimental investigation of the redox thermodynamics. Applied Catalysis B: Environmental 2017; 206: 104-114.

40. Germann H, Taglaiferri S and Geering HP. Differences in preand post-converter lambda sensor characteristics. Technical Report (No. 960335), SAE Technical Paper, 1996.

41. Auckenthaler TS, Onder CH and Geering HP. Control-oriented investigation of switch-type air/fuel ratio sensors. IFAC Proceedings Volumes 2002; 35(1): 331-336.

42. Gong J, Wang D, Li J et al. An experimental and kinetic modeling study of aging impact on surface and subsurface oxygen storage in three-way catalysts. Catalysis Today 2017; .

43. Miyamoto K, Takebayashi H, Ishihara T et al. Measurement of oxygen storage capacity of three-way catalyst and optimization of a/f perturbation control to its characteristics. Technical Report (No. 2002-01-1094), SAE Technical Paper, 2002.

44. Theis JR. An engine test to measure the oxygen storage capacity of a catalyst. Technical Report (No. 961900), SAE Technical Paper, 1996.

45. Ingram GA and Surnilla G. On-line oxygen storage capacity estimation of a catalyst. Technical Report (No. 2003-01-1000), SAE Technical Paper, 2003. 